MARCIA MARIA CARNEIRO

\title{
Metabolismo de quilomícrons e aterosclerose subclínica em portadores de hipercolesterolemia familiar heterozigótica
}

Tese apresentada à Faculdade de Medicina da Universidade de São Paulo para obtenção do título de Doutor em Ciências

Programa de: Cardiologia

Orientador: Prof. Dr. Raul Dias dos Santos Filho

SÃO PAULO

2011 
Dados Internacionais de Catalogação na Publicação (CIP)

Preparada pela Biblioteca da

Faculdade de Medicina da Universidade de São Paulo

Creprodução autorizada pelo autor

\section{Carneiro, Marcia Maria}

Metabolismo de quilomícrons e aterosclerose subclínica em portadores de hipercolesterolemia familiar heterozigótica / Marcia Maria Carneiro.-- São Paulo, 2011.

Tese(doutorado)--Faculdade de Medicina da Universidade de São Paulo. Programa de Cardiologia.

Orientador: Raul Dias dos Santos Filho.

Descritores: 1.Hipercolesterolemia familiar 2.Quilomícrons 3.Cinética 4.Aterosclerose 5.Lipídeos 6.Tomografia computadorizada 7.Triglicérides

USP/FM/DBD-230/11 
"A parte que ignoramos é muito maior que tudo quanto sabemos"

Platão 


\section{DEDICATÓRIA}

A minha família em especial a minha mãe Carmélia, minha irmã Maria e queridos sobrinhos Bebeto e Isadora que sempre foram meu alicerce e minha fortaleza em momentos decisivos e desafiadores, além de compreender minha ausência em situações tão importantes.

Ao meu amado Nelo que foi minha fonte de carinho, energia e alegria nessa longa jornada, tornando tudo um pouco mais fácil. 


\section{AGRADECIMENTOS}

Um agradecimento especial ao meu orientador Prof. Raul Dias Santos Filho que me aceitou como aluna, com as minhas limitações, me estimulou em momentos de desânimo e que sempre foi um grande exemplo de seriedade, competência, brilhantismo, entusiasmo e capacidade científica. Muito obrigada...

Ao Prof. Raul Maranhão por ter me recebido em seu laboratório e ter tornado possível a execução de meu trabalho, além de ter dividido sua grande experiência e conhecimento. 
Agradeço muitíssimo a todos os pacientes que aceitaram participar e me ajudar nesse trabalho e que sem os quais nada existiria.

As minhas queridas companheiras Ana Carolina e Carolina Pereira, amigas que adquiri e que foram colaboradoras fundamentais por todo esse tempo.

A Dra. Ana Paula pela grande ajuda e estímulo, e como um exemplo de comprometimento com os pacientes e com o serviço de Lípides.

Ao companheiro Marcio Miname por sua importante ajuda em diferentes fases desse trabalho.

A Dra. Viviane uma companheira muito incentivadora e sempre disposta a ajudar.

A querida Suely que foi também fonte de estímulo e ajuda.

Ao Dr. Wilson, Dr. Lilton, Leonardo, Otávio, Henrique, Paulo e Antônio que acompanharam a execução desse trabalho e deram grande contribuição com seus conselhos e trocas de experiências.

Ao Wanderley que com muita gentileza me auxiliou nas coletas e nos procedimentos e me ofertou tantas palavras de otimismo.

Aos companheiros do Laboratório de Lípides que me receberam e sempre me ajudaram.

Não poderia me esquecer de meus amigos Gardênia, Rose e Assis, além de todos os meus companheiros de trabalho, sempre dispostos a me substituir e apoiar. 
Esta tese está de acordo com as seguintes normas, em vigor no momento desta publicação:

Referências: adaptado de International Commitee of Medical Journals Editors (Vancouver).

Universidade de São Paulo. Faculdade de Medicina. Serviço de Biblioteca e Documentação. Guia de apresentação de dissertações, teses e monografias.

Elaborado por Anneliese Carneiro da Cunha, Maria Julia de A. L. Freddi, Maria F. Crestana, Marinalva de Souza Aragão, Suely Campos Cardoso, Valéria Vilhena. $2^{\mathrm{a}}$ ed. São Paulo: Serviço de Biblioteca e Documentação; 2005.

Abreviatura dos títulos dos periódicos de acordo com List of Journals Indexed in Index Medicus. 


\section{Sumário}

Lista de abreviaturas e símbolos

Lista de tabelas, figuras e anexos

Resumo

Summary

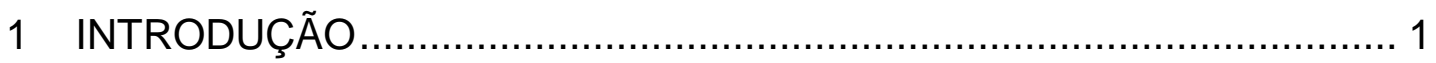

1.1 Hipercolesterolemia familiar ............................................... 2

1.2 Metabolismo de Quilomícrons .............................................. 3

1.2.1 Metabolismo de quilomícrons na HF ......................... 6

1.3. Calcificação Coronariana e Aterosclerose ...................................... 7

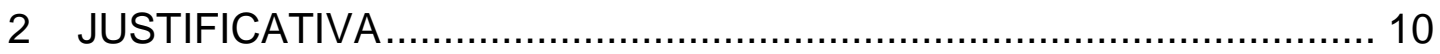

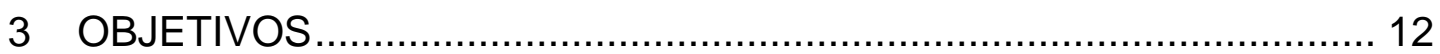

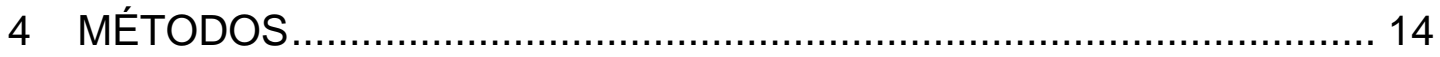

4.1 População ................................................................... 15

4.2 Critérios de inclusão..................................................... 15

4.3 Critérios de exclusão....................................................... 16

4.4 Avaliação e análise da CAC pela TCMD ................................ 17

4.5 Estudos da cinética dos quilomícrons artificiais ........................ 18

4.5.1 Preparo da emulsão de quilomícrons artificiais ............... 18

4.5.2 Análise dos constituintes da emulsão........................... 20

4.5.3 Estudos cinéticos com a emulsão de Quilomícrons Artificiais .......................................................... 21

4.5.4 Análise dos dados cinéticos ................................... 22

4.5.5 Considerações sobre proteção radiológica .................... 26

4.6 Análises bioquímicas dos pacientes ................................. 27

4.7 Determinação da mutação do receptor da LDL......................... 28

4.7.1 Extração do DNA .................................................... 28

4.7.2 Reação em cadeia da polimerase .................................. 29

4.7.3 Eletroforese em gel de agarose............................... 29

4.7.4 Sequenciamento automático .................................. 30 
4.8 Análise estatística .......................................................... 32

4.9 Implicações éticas ....................................................... 33

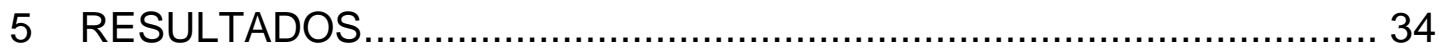

5.1 Comparação entre HF e controles normolipidêmicos ................. 35

5.2 Comparação dos grupos HF com ou sem CAC ........................ 40

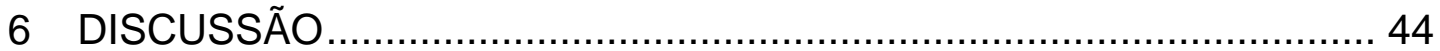

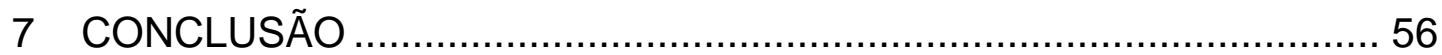

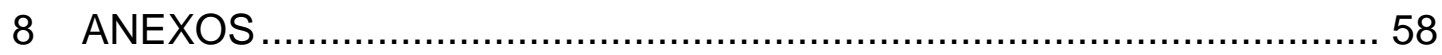

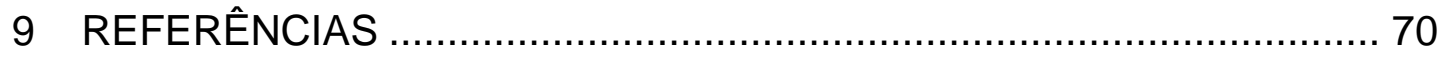




\section{Lista de abreviaturas}

\begin{tabular}{|c|c|}
\hline apo & Apolipoproteína \\
\hline apo A-I & Apolipoproteína A-I \\
\hline apo B & Apolipoproteína B \\
\hline CAC & Calcificação da artéria coronária \\
\hline CE & Colesterol éster \\
\hline CETP & Enzima transportadora de éster de colesterol \\
\hline DAC & Doença arterial crônica \\
\hline EBT & Tomografia de emissão de elétrons \\
\hline et al. & E todos \\
\hline HAS & Hipertensão arterial sistêmica \\
\hline HDL & Lipoproteína de alta densidade \\
\hline HF & Hipercolesterolemia familiar \\
\hline $\mathrm{HU}$ & Unidades Hounsfield \\
\hline IDL & Lipoproteína de densidade intermediária \\
\hline IMC & Índice de massa corporal \\
\hline LCAT & Enzima lecitina colesterol acil transferase \\
\hline LDL & Lipoproteína de baixa densidade \\
\hline LDL-C & LDL-colesterol \\
\hline LDL-R & Receptor da LDL \\
\hline LPL & Lipase lipoproteica \\
\hline LRP & Proteína relacionada ao receptor LDL \\
\hline $\min ^{-1}$ & Minutos $^{-1}$ \\
\hline
\end{tabular}




$\begin{array}{ll}\mathrm{n}^{\circ} & \text { Número } \\ \text { PCR } & \text { Proteína C reativa } \\ \text { PCR-as } & \text { Proteína C reativa altamente sensível } \\ \text { PCSK9 } & \text { Proteína convertase subtilisina/kexina tipo } 9 \\ \text { RLP } & \text { Proteína relacionada ao receptor da LDL } \\ \text { SR-BI } & \text { Receptor de membrana de tecido hepático } \\ \text { TC } & \text { Tomografia computadorizada } \\ \text { TCMD } & \text { Tomografia computadorizada com múltiplos detectores } \\ \text { TFR } & \text { Taxa fracional de remoção } \\ \text { TFL } & \text { Taxa fracional de lipólise } \\ \text { TFR } & \text { Taxa fracional de remoção } \\ { }^{3} \mathrm{H}-\mathrm{TG} & { }^{34} \mathrm{H} \text {-Trioleína } \\ \text { TFR }{ }^{14} \mathrm{C}-\mathrm{CE} & \text { Decaimento do 14C-éster de colesterol } \\ \text { TFR }{ }^{3} \mathrm{H}-\mathrm{TG} & \text { Decaimento do 3H-triglicerídeos } \\ \text { TG } & \text { Triglicerídeos } \\ \text { US-MEDPED } & \text { USA Make Early Diagnosis to Prevent Early Death } \\ & \end{array}$




\section{Lista de símbolos}

$\begin{array}{ll}< & \text { Menor que } \\ = & \text { Maior que } \\ \pm & \text { Igual } \\ \mathrm{g} / \mathrm{dL} & \text { Mais ou menos } \\ \mu \mathrm{m} & \text { Grama por decilitro } \\ \mathrm{mmHg} & \text { Micrômetro } \\ \mathrm{m} / \mathrm{s} & \text { Milímetros de mercúrio } \\ \mathrm{ml} / \mathrm{min} & \text { Metros por segundo } \\ \mathrm{n} & \text { Mililitros por minuto } \\ \mathrm{nm} & \text { Amostra } \\ \mathrm{p} & \text { Nanômetro } \\ \mathrm{r} & \text { Nível descritivo de probabilidade do teste } \\ \end{array}$




\section{Lista de tabelas}

Tabela 1. Dados demográficos dos pacientes HF e controles .35

Tabela 2. Dados laboratoriais ( $\mathrm{mg} / \mathrm{dL}$ ) dos pacientes HF e controles.... .36

Tabela 3. Parâmetros da cinética plasmática dos quilomícrons artificiais dos portadores de hipercolesterolemia familiar (HF) e controles

Tabela 4. Dados demográficos dos pacientes HF apresentando ou não CAC

Tabela 5. Dados Laboratoriais dos pacientes HF com ou sem CAC

Tabela 6. Parâmetros da cinética plasmática dos quilomícrons artificiais dos portadores de hipercolesterolemia familiar (HF) com e sem CAC 


\section{Lista de figuras}

Figura 1. Estrutura do quilomícron (modificado de Lehninger Principles of Biochemistry 2000; pg. 601).................................4

Figura 2. Modelo compartimental utilizado para análise de cinética plasmática dos quilomícrons artificiais

Figura 3a. Curva de decaimento do ${ }^{14} \mathrm{C}-\mathrm{CE}$ dos portadores de HF e controles

Figura 3b. Curva de decaimento do ${ }^{3} \mathrm{H}-\mathrm{TG}$ dos portadores de HF e controles

Figura 4a. Curva de decaimento do ${ }^{14} \mathrm{C}-\mathrm{CE}$ dos portadores de HF com e sem CAC

Figura 4b. Curva de decaimento do ${ }^{3} \mathrm{H}-\mathrm{TG}$ dos portadores de HF com e sem CAC 


\section{Lista de anexos}

Anexo 1. Tabela do diagnóstico genético dos pacientes portadores de HF .... 59 Anexo 2. Tabela com dados clínicos e laboratoriais do grupo controle .......60 60 Anexo 3. Tabela com os dados da cinética do grupo controle................... 61 Anexo 4. Tabelas dos dados da cinética dos pacientes HF com CAC ....... 62 Anexo 5. Tabelas dos dados da cinética dos pacientes HF sem CAC ....... 63 Anexo 6. Tabelas dos dados laboratoriais dos pacientes HF com CAC ...... 64 Anexo 7. Tabelas dos dados laboratoriais dos pacientes HF sem CAC ...... 65 Anexo 8. Termo de consentimento livre e esclarecido...........................66 66 


\section{Resumo}

Carneiro MM. Metabolismo de quilomícrons e aterosclerose subclínica em portadores de hipercolesterolemia familiar heterozigótica [tese]. São Paulo: Faculdade de Medicina, Universidade de São Paulo; 2011. 82p.

A hipercolesterolemia familiar (HF) é uma doença caracterizada por elevadas concentrações do colesterol das lipoproteínas de baixa densidade (LDL) e doença coronariana (DAC) prematura. Os remanescentes de quilomícrons são removidos principalmente pelo seu receptor específico (RLP), mas também pelo receptor da LDL. Este último encontra-se defeituoso na maior parte dos casos de HF e poderia levar a menor remoção plasmática dos quilomícrons. Há controvérsias se existem distúrbios do metabolismo dos quilomícrons em portadores de HF. Mais ainda não se sabe se estes defeitos poderiam contribuir para o desenvolvimento de DAC na HF. O objetivo deste estudo foi avaliar se portadores de HF apresentam defeitos na remoção plasmática de quilomícrons artificiais e seus remanescentes em relação a indivíduos normolipidêmicos. Foi avaliado também em estudo transversal se existe associação da cinética dos quilomícrons com a presença de DAC subclínica medida pela calcificação da artéria coronária (CAC). Foram estudados 36 pacientes portadores de HF e 50 controles normolipidêmicos pareados para idade e sexo. A remoção plasmática dos quilomícrons foi medida pelo decaimento radioisotópico da emulsão de quilomícrons artificiais injetada após jejum. A CAC foi determinada por tomografia computadorizada cardíaca nos portadores de HF. As taxas fracionais de remoção (TFR) dos quilomícrons e de seus remanescentes representadas pelo decaimento do ${ }^{14} \mathrm{C}$-éster de colesterol (TFR ${ }^{14} \mathrm{C}$-CE em $\mathrm{min}^{-1}$ ) foram menores nos portadores de HF em comparação aos normolipidêmicos: mediana (intervalos) 0,0013 (1,5.10 $\left.{ }^{9} ; 0,082\right)$ vs. $0,012\left(1,51 \cdot 10^{-9} ; 0,017\right) p=0,001$. Não houve diferença em relação à remoção dos triglicérides da emulsão representada pelo decaimento da ${ }^{3} \mathrm{H}$-triglicérides (TFR ${ }^{3} \mathrm{H}$-TG em min ${ }^{-1}$ ) entre os grupos: 0,027 $(0,0004 ; 0,23)$ e $0,03(0,0004 ; 0,4)$ respectivamente nos grupo HF e controle $(p=0,26)$. Não foram encontradas diferenças significativas nas TFR tanto do ${ }^{14}$ C-CE $0,0007\left(1,47.10^{-9} ; 0,082\right)$ e $0,0013\left(1,6 \cdot 10^{-9} ; 0,038\right) p=0,67$ como do ${ }^{3} \mathrm{H}$-TG $0,025 \quad(0,0004 ; 0,07)$ e $0,0029 \quad(0,009 ; \quad 0,23), \quad p=0,80$ respectivamente nos portadores de HF apresentando $(n=20)$ ou não CAC $(n=16)$. Em conclusão os portadores de HF apresentaram diminuição significativa da remoção dos quilomícrons e seus remanescentes em comparação com normolipidêmicos. Contudo, não foi encontrada associação entre esses distúrbios e a presença da DAC subclínica.

Descritores: 1.Hipercolesterolemia Familiar 2.Quilomícrons 3.Cinética 4.Aterosclerose 5.Lipídeos 6.Tomografia computadorizada 7.Triglicérides 


\section{Summary}

Carneiro MM. Chylomicrons metabolism and subclinical atherosclerosis in patients with heterozygous familial hypercholesterolemia [thesis]. São Paulo: Faculdade de Medicina, Universidade de São Paulo; 2011. 82p.

Familial hypercholesterolemia $(\mathrm{FH})$ is characterized by high concentrations of low density lipoproteins (LDL) cholesterol and early onset of coronary artery disease (CAD). Chylomicron remnants are removed mainly by their specific receptors (RLP) but also by the LDL receptor. The latter is defective in most cases of $\mathrm{FH}$ and could lead to lower plasma removal of chylomicrons and their remnants. There is controversy whether there are disorders of chylomicron metabolism in patients with $\mathrm{FH}$. Moreover, it is unclear if these defects could contribute to the development of CAD in FH. The aim of this study was to evaluate whether there are defects on the removal from plasma of chylomicrons and their remnants in $\mathrm{FH}$ patients in comparison with normolipidemic subjects. We also evaluated in a cross sectional study the association of chylomicron kinetics with the presence of subclinical CAD represented by coronary artery calcification (CAC). We studied 36 patients with $\mathrm{FH}$ and 50 normolipidemic controls matched for age and sex. The plasma removal of chylomicrons was measured by isotopic decay of artificial chylomicron emulsion injected after fasting. CAC was determined by cardiac computed tomography in $\mathrm{FH}$ patients. The fractional catabolic rates (FCR) of chylomicrons and remnants removal represented by ${ }^{14} \mathrm{C}$-cholesteryl ester decay $\left({ }^{14} \mathrm{C}\right.$-CE FCR in $\left.\mathrm{min}^{-1}\right)$ were lower in $\mathrm{FH}$ in comparison with normolipidemics: median (ranges) $0.0013\left(1.47 .10^{-9} ; 0.082\right)$ vs. 0.012 $\left(1.51 .10^{-9}, 0.169\right) p=0.001$. There was no difference regarding the removal of emulsion triglyceride represented by ${ }^{3} \mathrm{H}$-triglyceride decay of ( ${ }^{3} \mathrm{H}$ - TG FCR in $\left.\mathrm{min}^{-1}\right)$ between the groups: $0.026(0.0004 ; 0.23)$ and $0.031(0.0004 ; 0.4)$ respectively in $\mathrm{FH}$ and in normolipidemics $(p=0.264)$. There were no significant differences in both the ${ }^{14} \mathrm{C}$-CE FCR $0.0007\left(1.47 .10^{-9} ; 0.08\right)$ and $0.0013\left(1.61 .10^{-9} ; 0.038\right) \mathrm{p}=0.67$ and in the ${ }^{3} \mathrm{H}-\mathrm{TG}$ FCR 0.025 (0.0004; $0.075)$ and $0.029(0.0095 ; 0.23), p=0.80$ respectively in $\mathrm{FH}$ patients presenting $(n=20)$ or not CAC $(n=16)$. In conclusion patients with $\mathrm{FH}$ had a significant decrease on the removal from plasma of chylomicrons and their remnants compared with normolipidemics. However, no association between these disorders and the presence of CAC was found.

Descriptors: 1.Familial Hypercholesterolemia 2.Chylomicrons 3.Kinetics 4.Atherosclerosis 5.Lipids 6.Computed Tomography 7.Triglycerides 
1 INTRODUCÃ̃O 


\subsection{Hipercolesterolemia familiar}

A hipercolesterolemia familiar (HF) é uma doença autossômica dominante do metabolismo de lipoproteínas, caracterizada por elevadas concentrações plasmáticas de lipoproteína de baixa densidade (LDL), xantomas tendinosos e doença coronária prematura ${ }^{1,2}$. A incidência na forma heterozigótica é de aproximadamente 1 para cada 300-500 indivíduos ${ }^{1,3-5}$. A doença resulta geralmente de mutações no receptor de LDL-colesterol (LDL-C) no fígado. O gene do receptor de LDL foi clonado e mapeado na região 19p13. 1-13.3 e foram detectadas até o momento mais de 1600 mutações $^{4-6}$.

A penetrância do gene é de quase $100 \%$, que implica em acometimento em cerca de $50 \%$ da prole de pais afetados sendo homens e mulheres com chances iguais de acometimento ${ }^{4,5,7}$.

Atualmente outros "loci" têm sido identificados como responsáveis pelo desenvolvimento da HF, dentre eles, o mais comum é o defeito familiar da apolipoproteína $B$, que apresenta baixa afinidade para o receptor de LDL (LDLR), e menos frequentes, apresentam-se a HF relacionada ao cromossomo 1p32, HF autossômica recessiva, deficiência de colesterol 7alfa-hidrolase, sitosterolemia familiar e mutações da PCSK9 ${ }^{2,8,9}$.

Segundo o grupo US-MEDPED o diagnóstico clínico da HF é feito pela detecção de níveis de LDL-C acima do percentil 95 da população, e 
história de dislipidemia familiar e coronariopatia precoce ${ }^{10}$. Uma importante característica da HF é o risco cumulativo de coronariopatia precoce fatal e não fatal acometendo cerca de 50\% dos homens de até 50 anos e 30\% das mulheres de até 60 anos ${ }^{11,12}$. Dessa forma o tratamento hipolipemiante agressivo e precoce da HF é imperioso.

Um dado importante é que o curso da doença aterosclerótica coronária (DAC) da HF é variável podendo alguns indivíduos apresentar doença de forma mais precoce que outros, apesar da elevação do LDL-C. Isso chama a atenção para outras variáveis que não somente concentrações elevadas de colesterol no sangue. Assim, vários trabalhos relacionam fatores como HDL-C baixo, triglicérides elevados, lipoproteína (a) [Lp(a)] aumentada, hipertensão arterial sistêmica (HAS), obesidade , tabagismo e resistência insulínica com o desenvolvimento de aterosclerose de forma mais acelerada em indivíduos com $\mathrm{HF}^{13-30}$.

\subsection{Metabolismo de Quilomícrons}

Quilomícrons são lipoproteínas ricas em triglicérides formados no enterócito, que carreiam lípides da dieta e vitaminas lipossolúveis absorvidas no trato intestinal para o fígado e tecidos periféricos, como o tecido adiposo e músculos esqueléticos ${ }^{31-33}$. Uma vez secretados nos vasos linfáticos, os quilomícrons adquirem pequenas lipoproteínas chamadas de Apolipoproteínas (apo), sendo as mais comuns a apo E, CII e CIII que modulam a atividade 
das enzimas lipolíticas ou agem como ligantes para os receptores celulares. Uma outra apo denominada apo B48 tem função estrutural nas partículas dos quilomícrons ${ }^{33}$.

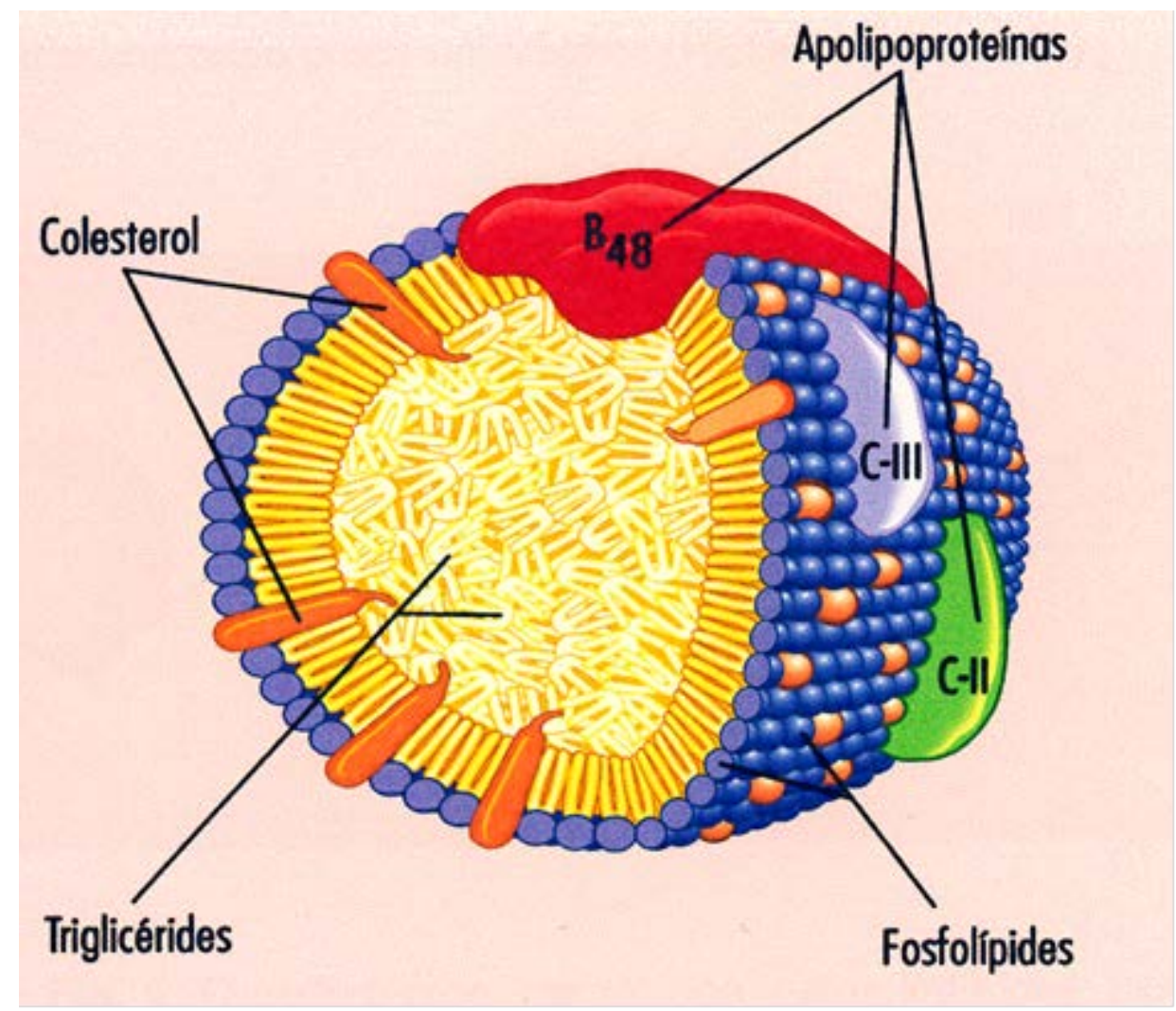

Figura 1. Estrutura do quilomícron (modificado de Lehninger Principles of Biochemistry 2000; pg. 601).

$\mathrm{Na}$ circulação sanguínea os quilomícrons se ligam à superfície endotelial dos capilares e a hidrólise de triglicérides acontece por ação da lipase lipoprotéica (LPL), liberando assim ácidos graxos para as células ao redor. Depois dessa fase inicial os remanescentes de quilomícrons depletados de triglicérides são sequestrados no espaço de Disse e se 
ligam a receptores hepáticos por intermédio da apo E. Dentre estes podemos citar o receptor RLP (proteína relacionada ao receptor da LDL) sendo este o principal receptor para remoção dessas lipoproteínas em estudos realizados em animais de experimentação, ligação a proteoglicanos (HSPG) para posterior introjeção no hepatócito, além do próprio receptor da LDL (receptor $B, E)^{32}$.

$\mathrm{Na}$ literatura vários trabalhos sugerem que o catabolismo deficiente dos quilomícrons está relacionado com desenvolvimento de aterosclerose. Acredita-se que a geração de células espumosas por deposição direta desses remanescentes nos vasos, além de interferência com o transporte reverso do colesterol seriam possíveis mecanismos de desenvolvimento da aterosclerose $^{34-36}$.

Dentre as diversas metodologias utilizadas para se avaliar a cinética plasmática dos quilomícrons podemos citar as emulsões lipídicas similares a pequenos quilomícrons marcadas com radioisótopos ${ }^{31,37-39}$. Embora sua cinética de remoção plasmática seja avaliada no jejum e não no período pósprandial, diferentemente dos testes com vitamina A ou apo B48 esta oferece uma visão integrada e clara dos passos do catabolismo dos quilomícrons e seus remanescentes no plasma. Diferentemente dos outros testes ela não sofre influência da absorção intestinal de gordura e nem das dificuldades de oriundas da mistura dos quilomícrons com as VLDL que ocorrem no período pós-prandial ${ }^{37}$.

Vários estudos desenvolvidos pelo grupo do Prof. Raul C. Maranhão no Instituto do Coração do HCFMUSP mostraram que a cinética dos 
quilomícrons artificiais está alterada em pacientes portadores dislipidemias e ou doença arterial coronária $(D A C)^{37,40-42}$. Nesses estudos, foram identificados defeitos tanto na lipólise como na remoção dos remanescentes de quilomícrons, sendo que em portadores de DAC estes mecanismos se encontram diminuídos ${ }^{37}$. Outros estudos mostraram também que a cinética de quilomícron diminuída, é marcadora da gravidade angiográfica e de um curso mais grave da DAC ${ }^{40,41}$.

Foi demonstrado também que existe correlação inversa entre a taxa fracional de remoção do remanescente do quilomícron artificial e as concentrações de LDL-c no plasma ${ }^{43}$ em indivíduos sem HF. Além disso, estudos mostraram que estatinas usadas em doses variáveis e que sabidamente aumentam a expressão do receptor da LDL no fígado, levam a um maior catabolismo das emulsões de quilomícrons artificiais em seres humanos. Esses dados comprovam o papel do receptor da LDL na remoção das emulsões ${ }^{38,43,44}$.

\subsubsection{Metabolismo de quilomícrons na HF}

O receptor da LDL além de ligar-se à apo B100, que é a porção protéica da LDL, apresenta alta afinidade pela apo E que é uma das principais lipoproteínas dos remanescentes de quilomícrons. Dessa forma seria de se esperar que a diminuição da expressão do receptor da LDL poderia levar à diminuição do clearance plasmático dos remanescentes de quilomícrons ${ }^{45}$. 
Estudos em animais e no Homem mostram controvérsias se realmente ocorrem defeitos na remoção dos quilomícrons e remanescente em portadores de HF. Sendo que alguns estudos mostram diminuição da remoção dos remanescentes e outros não encontraram alterações. Isso pode ter ocorrido devido a diferenças nos desenhos de estudo, métodos de análise empregados, não caracterização adequada das populações de HF, heterogeneidade das partículas geradas no período pós-prandial , presença de fatores externos obesidade abdominal e resistência insulínica concomitantes $^{45-51}$.

Desse modo percebe-se que o tema ainda permanece com muitas respostas a serem esclarecidas. Além disso, não existe comprovação ainda da importância dos quilomícrons no processo aterosclerótico de portadores de HF aonde as elevadas concentrações de LDL-colesterol têm papel fundamental.

\subsection{Calcificação Coronariana e Aterosclerose}

Uma forte correlação entre a calcificação da artéria coronária (CAC) identificada pela fluoroscopia ou por exame anatomopatológico e doença arterial coronária é conhecida desde $1961^{52,53}$. Pesquisas mais recentes sugerem que o cálcio já está presente na placa aterosclerótica nos seus primeiros estágios quando a lesão é constituída apenas de estrias de 
gordura ${ }^{54}$. Entretanto, nesse estágio o cálcio não pode ser identificado por meio dos métodos não invasivos atuais.

Dentre os métodos não invasivos disponíveis na prática clínica temos a tomografia computadorizada cardíaca que nos permite calcular o escore de cálcio coronário. A medida que a lesão aterosclerótica progride, com a adição de colesterol, células inflamatórias e tecido fibrótico, o cálcio se acumula sob a forma de placas, na base da íntima e torna-se identificável pela tomografia computadorizada. Simons et al. $^{53}$ analisaram cortes histológicos seqüenciais, das porções iniciais até as caudais, de 525 artérias coronárias. Embora não houvesse cálcio em todas as lesões, foi encontrada uma correlação importante entre a quantidade de cálcio e a quantidade de aterosclerose existente em cada artéria coronária. As lesões sem calcificação, na sua quase totalidade, não apresentavam obstrução significativa do lúmen coronário. Isso demonstra que a identificação do cálcio e sua quantificação permitem, de certa forma, dimensionar o grau de doença arterial coronária existente .

Estudo semelhante de Rumberger et al. ${ }^{54}$ correlacionando a quantificação do cálcio coronariano pela tomografia ultra-rápida de corações em necrópsia e a quantificação histopatológica ratificaram esses dados.

Estudos angiográficos e com ultrassom coronário também mostraram que a CAC se correlaciona com a carga de placa aterosclerótica ${ }^{55,56}$. A carga de placa aterosclerótica por sua vez se correlaciona com o risco de eventos coronários ${ }^{57-59}$. 
Além disso, vários estudos em indivíduos assintomáticos ou não para doença arterial coronária têm demonstrado correlação da CAC, embora não linear, com a obstrução da luz do vaso ${ }^{60,61}$.

Atualmente a CAC pode ser detectada não somente pela tomografia de emissão de elétrons $(E B T)^{62-64}$, mas também por modernos tomógrafos computadorizados com múltiplos detectores $(\mathrm{TCMD})^{65}$. Estudos mais recentes têm relatado a superioridade do TCMD em relação ao EBT, na melhor precisão em definição de placas de cálcio, devido ao fato da TCMD permitir a aquisição simultânea de até 320 cortes, 230ms de rotação do scanner e até $75 \mathrm{~ms}$ de resolução temporal ${ }^{66-68}$. Estes aperfeiçoamentos têm a vantagem da considerável rapidez de cobertura do volume cardíaco, quando comparado com a EBT; o aumento da velocidade do aparelho de tomografia computadorizada (TC) permite uma simples pausa respiratória durante o exame, associado com espessura de cortes mais finos, levando a melhor resolução espacial o que é indispensável para exames de alta resolução ${ }^{67,69}$. Dados oriundos de nossa população mostram que portadores de HF apresentam uma maior prevalência e gravidade da CAC quando comparados a indivíduos normais ${ }^{70}$. Sendo que estas apresentam associação com aumento da idade e com valores elevados do colesterol do plasma ${ }^{71,72}$. 
2 JUSTIFICATIVA 
Não existe consenso na literatura sobre possível anormalidade na remoção dos quilomícrons e seus remanescentes em portadores de HF. Previamente foi demonstrado que existe correlação inversa entre os valores de LDL-colesterol e a remoção dos remanescentes de quilomícrons quando estudados pela técnica dos quilomícrons artificiais. Sabe-se também que procedimentos que aumentam a expressão desse receptor, como o uso de estatinas, aceleram a remoção dos remanescentes de quilomícrons como previamente demonstrado. Mais ainda, é desconhecido se possíveis defeitos nas vias de remoção das lipoproteínas pós-prandiais poderiam associar-se ou não com a presença de aterosclerose numa doença como a HF onde claramente elevações importantes do LDL-colesterol são o principal fator de risco.

A CAC determinada pela tomografia computadorizada cardíaca é uma marcadora da presença da aterosclerose que se associa com a presença de obstrução luminal e com um maior risco de eventos clínicos. Já foi demonstrado de forma clara que a CAC é mais frequente e grave em portadores de HF do que em normolipidêmicos. Ainda não foi estudada a cinética de quilomícrons em portadores de HF com e sem aterosclerose, especialmente na forma subclínica, como no caso da detecção da CAC em indivíduos assintomáticos e sem manifestação prévia de doença coronária. 


\section{OBJETIVOS}


O objetivo principal deste estudo foi verificar se há diferenças na remoção plasmática de quilomícrons avaliados pela técnica dos quilomícrons artificiais entre portadores de HF e indivíduos normolipidêmicos.

Objetivamos avaliar também, de forma transversal, se existem diferenças na remoção plasmática dos quilomícrons artificiais entre portadores de HF que apresentam ou não doença coronariana subclínica representada pela CAC detectada pela tomografia computadorizada. 
4 MÉTODOS 


\subsection{População}

Foram incluídos neste estudo de maneira transversal, 36 pacientes do Ambulatório da Unidade Clínica de Lípides do InCor HCFMUSP previamente diagnosticados com HF pelos critérios do US MED PED ${ }^{10}$ e secundariamente 20 pacientes confirmados por genotipagem da mutação do receptor da LDL. Estes não apresentavam antecedentes de DAC e haviam sido submetidos previamente à avaliação da CAC por TCMD. Além disso, foram estudados de forma retrospectiva 50 indivíduos normolipidêmicos, sem manifestações prévias de DAC, definidos como portadores de colesterol total $<240 \mathrm{mg} / \mathrm{dL}$ e triglicérides $<250 \mathrm{mg} / \mathrm{dL}$, pareados por idade e sexo oriundos do banco de dados do laboratório de Metabolismo de Lípides do InCor HCFMUSP.

\subsection{Critérios de inclusão}

Os indivíduos elegíveis para inclusão no estudo deveriam apresentar todos os seguintes critérios:

1. Termo de Consentimento Livre e Esclarecido por escrito lido, discutido e assinado pelo indivíduo antes do início de quaisquer procedimentos relacionados ao estudo; 
2. Homem ou Mulher de pelo menos 18 anos de idade até 70 anos. Indivíduos do sexo feminino de preferência deveriam estar na pósmenopausa e sem o uso de reposição hormonal;

3. Portadores de hipercolesterolemia familiar;

4. Indivíduos sem uso de estatinas há pelo menos seis semanas; para indivíduos em uso prévio de estatinas foi feito "washout" da medicação por seis semanas. É importante salientar que não existe evidência de um risco elevado de eventos coronários pela suspensão temporária de estatinas mesmo em indivíduos sabidamente coronarianos estáveis ${ }^{73}$.

5. Submissão prévia a Tomografia Computadorizada de coronárias para avaliação do Escore de cálcio.

\subsection{Critérios de exclusão}

1. Presença de doença arterial coronariana, cérebrovascular e periférica estabelecida;

2. Insuficiência Cardíaca grave atual (Classe III ou IV da associação de Cardiologia de Nova Iorque);

3. Comprometimento renal diagnosticado;

4. Doença Hepática atual;

5. Doenças da tireóide não controlada; 
6. Diabetes Mellitus;

7. Gestantes ou Lactantes;

8. Mulheres em idade reprodutiva sem uso de método anticoncepcional adequado;

9. Neoplasia maligna diagnosticada;

10. Uso de corticosteróides, terapia de reposição hormonal exceto anticoncepcionais;

\subsection{Avaliação e análise da CAC pela TCMD}

A avaliação do escore de cálcio foi previamente realizada em aparelho de tomografia computadorizada com múltiplas colunas de detectores (Aquilleon $64^{R}$ - Toshiba, com 64 detectores). Este equipamento tem capacidade de adquirir até 160 imagens por segundo, sendo o sistema de resolução temporal máxima de 125-250 ms e a espessura mínima de corte de $0,5 \mathrm{~mm}$. Os pacientes não receberam qualquer tipo de contraste e o tempo total de duração do exame foi de 5 a 10 minutos. Foi utilizado "trigger" prospectivo e espessura de corte de $3 \mathrm{~mm}$. As imagens foram analisadas em estação de trabalho da VITREA 2 (Vital Images, Minnetonka, EUA). A análise dos dados foi realizada seguindo um protocolo cujo limiar de densidade para a definição do cálcio foi de 130 unidades Hounsfield (HU) e determinadas através de "software" semiautomático no qual a quantificação 
de CAC foi avaliada pelo escore de Agatston ${ }^{74}$. As imagens foram analisadas por dois médicos, tecnicamente treinados e experientes para a aquisição e avaliação da CAC. A CAC foi considerada presente para valores de escore $\geq 1$

\subsection{Estudos da cinética dos quilomícrons artificiais}

O estudo da cinética foi realizado por meio de coleta de sangue basal dos indivíduos em jejum e após a injeção da emulsão lipídica marcada com radioisótopos. Foram coletadas amostras de sangue subsequentes até 60 minutos.

\subsubsection{Preparo da emulsão de quilomícrons artificiais}

O preparo da emulsão de quilomícrons artificiais foi realizado conforme descrição de Maranhão et al. $^{31,37}$. Emulsões de lípides frios contendo colesterol $2 \%$, oleato de colesterol $6 \%$, lecitina $23 \%$, e trioleína 69\% foram dissolvidas em clorofórmio: metanol, 2:1 e pipetados em frascos de cintilação, onde foram acrescidos os lípides radioativos formados pelo ${ }^{14} \mathrm{C}$-oleato de colesterol $\left({ }^{14} \mathrm{C}\right.$-CE) e ${ }^{3} \mathrm{H}$-trioleína $\left({ }^{3} \mathrm{H}-\mathrm{TG}\right)$. As misturas obtidas passaram por um processo de secagem sob fluxo de nitrogênio, sendo então mantidas durante 12 horas em dessecador a vácuo, previamente esterilizado por luz ultravioleta a $4^{\circ} \mathrm{C}$, para completa evaporação dos solventes 
orgânicos residuais. A essa mistura seca acrescentou-se $6,0 \mathrm{~mL}$ de solução de $\mathrm{NaCl}$ estéril, com densidade de 1,101 g/mL e pH 7,0. As emulsões foram preparadas por meio de irradiação ultrassônica das misturas lipídicas em meio aquoso salino, utilizando-se um disrruptor de células, Branson Cell Disruptor (Branson Ultrasonics Corp, modelo B 450), equipado com ponta de titânio de $1 \mathrm{~cm}$ de diâmetro, com uma potência de 70-80 watts, durante 30 minutos, sob fluxo de nitrogênio a uma temperatura de 50 a $55^{\circ} \mathrm{C}$ Para obter-se uma emulsão com partículas homogêneas e purificadas, de tamanho e densidade desejados, a emulsão foi submetida a duas etapas de centrifugação em gradiente descontínuo de densidade, utilizando-se a ultra centrifuga Sorvall (modelo OTD-COMBI, Wilmington, EUA) e rotor TH-641. $\mathrm{Na}$ primeira etapa, acrescentou-se ao volume das emulsões obtidas por irradiação ultrassônica, soluções salinas com densidades 1,065g/mL , $1,020 \mathrm{~g} / \mathrm{mL}$ e 1,006 g/mL, nesta ordem. As emulsões foram ultra centrifugadas a 12.000 rotações por minuto, a $22^{\circ} \mathrm{C}$, durante 15 minutos. Ao término da ultracentrifugação, foram desprezados $0,5 \mathrm{~mL}$ do sobrenadante, sendo o volume restante submetido a uma segunda etapa de purificação por ultracentrifugação a 36.000 rotações por minuto, a $22^{\circ} \mathrm{C}$, durante 25 minutos. Ao término desta segunda etapa, foram aspirados 3,0 $\mathrm{mL}$ do sobrenadante, resultando na emulsão purificada e homogeneizada, utilizada neste estudo. As emulsões foram imediatamente esterilizadas, pela passagem em filtros com porosidade de 0,22 $\mu \mathrm{m}$ de diâmetro (Millipore, São Paulo), e armazenadas em frascos estéreis. Toda a vidraria utilizada no preparo das emulsões foi submetida a um processo de despirogenização, através de 
vapor seco a $180^{\circ} \mathrm{C}$ durante 2 horas e esterilização, em vapor úmido a $120^{\circ} \mathrm{C}$, durante 30 minutos. Os materiais plásticos foram esterilizados por meio de exposição à luz ultravioleta de onda curta, que apresenta um componente com comprimento de onda de 253,7 nm, por um período de 12 horas. Todo o procedimento de preparo das emulsões foi realizado em capela de fluxo de ar laminar vertical. Alíquotas das emulsões artificiais foram submetidas ao teste de esterilidade no setor de Bacteriologia do Laboratório Central do Hospital das Clínicas da Universidade de São Paulo e pirogenicidade "in vivo", no Instituto de Medicina Nuclear do HC-FMUSP.

\subsubsection{Análise dos constituintes da emulsão}

As emulsões, após o preparo, apresentaram a seguinte composição química percentual: triglicérides 76,5 \pm 4,1\%; colesterol livre 1,9 \pm 0,3\%; éster de colesterol 11,2 $\pm 3,0 \%$ e fosfolípides $10,4 \pm 1,3 \%$. A trioleína foi quantificada por método enzimático comercial (Sigma Chemical Co., St Louis, E.U.A.), e o fosfolípide por precipitação em ácido tricloroacético . A separação entre o colesterol livre e o esterificado, foi obtida por cromatografia de camada delgada em sílica gel 60 H (0,5 mm de espessura), desenvolvida em sistema de solventes n-hexano/éter etílico/ácido acético glacial (70 ml: $30 \mathrm{ml}: 1,0 \mathrm{ml}$ ). O colesterol livre e o oleato de colesterol foram quantificados pelo método de Zlatikis $^{75}$. 


\subsubsection{Estudos cinéticos com a emulsão de Quilomícrons Artificiais}

Os participantes do estudo chegavam ao laboratório de Metabolismo de Lípides do Instituto do Coração do HC-FMUSP no período da manhã, em jejum de pelo menos 12 horas. Após a coleta das amostras de sangue para as determinações de concentração plasmática de colesterol total, LDL-C, HDL-C, VLDL-C, triglicérides, apo A-I, apo B, Lipoproteína -Lp (a), proteína $C$ reativa $(P C R)$, glicose, creatinofosfoquinase total (CPK), alanina aminotransferase (TGP) nos portadores de HF, dava-se início aos estudos cinéticos da emulsão de quilomícrons artificiais. Era injetado na veia cerca de 100 microlitros de emulsão de quilomícrons artificiais, contendo 148 kBq (4 $\mu \mathrm{Ci})$ de ${ }^{3} \mathrm{H}$-trioleína $\left({ }^{3} \mathrm{H}\right.$-TG) e $74 \mathrm{kBq}(2 \mu \mathrm{Ci})$ de ${ }^{14} \mathrm{C}$-oleato de colesterol $\left({ }^{14} \mathrm{C}-\mathrm{CE}\right)$. Após a injeção, por meio de outra punção venosa em braço contralateral, foram colhidas amostras sanguíneas (5 ml) em tubos de ensaio contendo 50 microlitros de heparina sódica, em intervalos de tempo pré-estabelecidos $(2,4,6,10,15,20,30,45$ e 60 minutos), mantendo-se a cateterização venosa com infusão lenta de soro fisiológico a 0,9\%. As amostras sanguíneas foram centrifugadas a 2.700 rpm, durante 10 minutos, em centrífuga Sorvall (modelo RT7,Wilmington,EUA), para obtenção de plasma. Alíquotas de plasma $(1,0 \mathrm{~mL})$ foram pipetados em frascos de cintilação. Foram acrescentados $7 \mathrm{ml}$ de solução cintiladora PPO/POPOP/ triton X-100/tolueno (5g:0,5g:333 mL:/667 mL) para a determinação da radiatividade presente nas amostras coletadas, utilizando-se um contador 
Beta (Packard, modelo 1660 TR,EUA). As contagens obtidas foram utilizadas para o cálculo das curvas de decaimentos plasmáticos e dos parâmetros cinéticos dos componentes lipídicos radioativos da emulsão.

\subsubsection{Análise dos dados cinéticos}

As cinéticas de ${ }^{3} \mathrm{H}$-TG e do ${ }^{14} \mathrm{C}$-CE fornecem informações distintas sobre o comportamento dos quilomícrons no plasma. A remoção plasmática dos ${ }^{3} \mathrm{H}$-TG da emulsão reflete o processo de lipólise dos quilomícrons artificiais, enquanto a remoção do éster de ${ }^{14} \mathrm{C}$-CE reflete a remoção do remanescente pelo fígado. As contagens de radioatividades obtidas nas amostras de plasma dos pacientes nos tempos avaliados durante 60 minutos foram utilizadas para a determinação das curvas de decaimento plasmático e cálculo dos parâmetros cinéticos dos componentes lipídicos radioativos da nanoemulsão, por meio de análise compartimental, com a utilização de um programa computacional desenvolvido para análise de cinética de nanoemulsões por C.H Mesquita, do Instituto de Pesquisas Energéticas e Nucleares da Universidade de São Paulo, São Paulo, programa AnaComp versão $4.1^{76}$.

No modelo utilizado (figura 2), a análise da cinética da nanoemulsão foi realizada por avaliações isoladas das remoções plasmáticas de seus componentes lipídicos radioativos, pelo fato dos mesmos apresentarem comportamentos diferentes. Assim como no metabolismo dos quilomícrons naturais, os triglicérides da nanoemulsão são hidrolisados durante o 
metabolismo, enquanto que o oleato de colesterol permanece no interior da partícula até a captação da mesma pelo fígado.

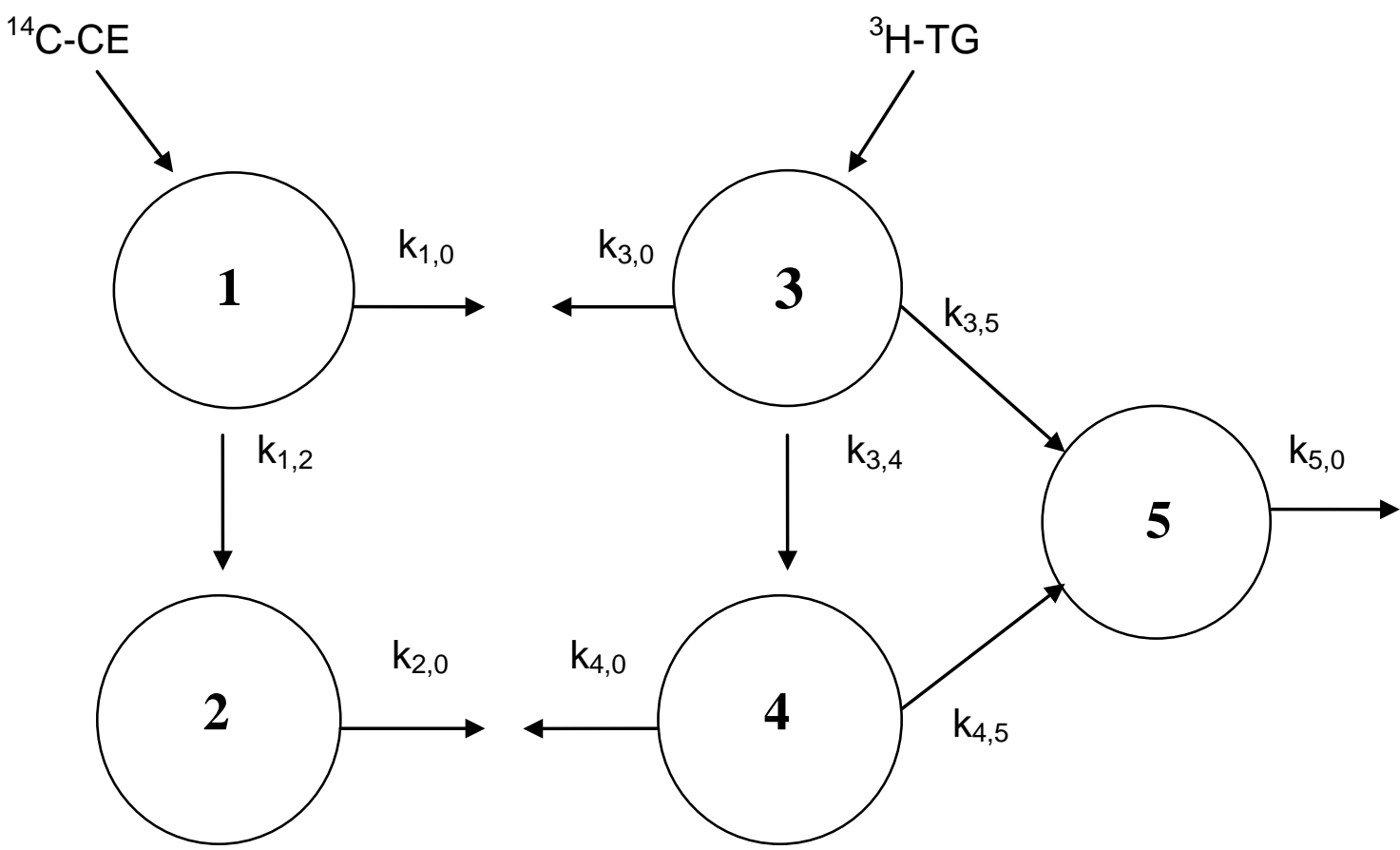

Figura 2. Modelo compartimental utilizado para análise de cinética plasmática dos quilomícrons artificiais

A curva de remoção plasmática do ${ }^{14} \mathrm{C}$-colesterol esterificado $\left({ }^{14} \mathrm{C}\right.$-CE $)$ reflete a cinética do colesterol esterificado e apresenta um perfil bi exponencial com um rápido decaimento inicial seguido de outro mais lento. Esse perfil levou à adoção de um modelo com dois compartimentos que representam o colesterol esterificado dos quilomícrons artificiais no espaço intravascular, tal como foi injetado (compartimento1) ou na partícula remanescente resultante do processo de lipólise (compartimento 2). 
A curva de remoção plasmática dos ${ }^{3} \mathrm{H}$-triglicérides $\left({ }^{3} \mathrm{H}\right.$-TG) representa a cinética das moléculas de triglicérides. Embora essa curva apresente as mesmas características da curva de remoção do ${ }^{14} \mathrm{C}-\mathrm{CE}$, o seu decaimento é mais rápido devido à ação da LLP. A cinética do ${ }^{3} \mathrm{H}-T G$ é representada por três compartimentos: os triglicérides na partícula, tal como foi injetado na circulação sanguínea (compartimento 3), as partículas remanescentes (compartimento 4) e os ácidos graxos livres derivados da hidrólise dos triglicérides (compartimento 5).

A partir desse modelo e com base no método dos mínimos quadrados não linear, foram calculadas as taxas fracionais de transferências $\left(k_{x}, y\right)$ dos lípides marcados entre os compartimentos ou para o espaço extravascular.

\section{Análise Cinética do ${ }^{14} \mathrm{C}$-colesterol éster}

O compartimento número 1 representa a emulsão marcada com o ${ }^{14} \mathrm{C}-\mathrm{CE}$, introduzida no espaço intravascular.

- $\mathrm{k}_{1,0}$ representa a fração da emulsão que é retirada do compartimento plasmático por meio de via não específica;

- $\mathbf{k}_{1,2}$ representa a fração da emulsão que sofre a ação da LLP, perdendo os triglicérides e se transformando em uma partícula menor; 
O compartimento número 2 representa o remanescente de quilomícron resultante da ação lipolítica;

- $\mathrm{k}_{2,0}$ representa a fração de remanescente de quilomícron que é removida do compartimento plasmático, por meio de captação principalmente hepática.

\section{Análise Cinética do ${ }^{3} \mathrm{H}$-triglicérides}

O compartimento número 3 representa a emulsão marcada com ${ }^{3} \mathrm{H}-\mathrm{TG}$, injetada na circulação sanguínea.

- $\mathrm{k}_{3,0}$ representa a fração da emulsão que é removida do compartimento plasmático por meio de via não específica;

- $k_{3,4}$ representa a fração da emulsão que sofre a ação da LLP, perde triglicérides se transforma no remanescente de quilomícron; este equivale ao $\mathrm{k}_{1,2}$;

- $\mathrm{k}_{3,5}$ representa a fração de ácidos graxos livres formada a partir da hidrólise dos triglicérides, pela ação da LLP sobre os quilomícrons.

O compartimento $\mathrm{n}^{\circ} 4$ representa o remanescente de quilomícron.

- $\mathrm{k}_{4,5}$ representa a fração de ácidos graxos livres formada a partir da hidrólise dos triglicerídeos pela ação da LLP sobre os remanescente de quilomícrons.

- $\mathrm{k}_{4,0}$ representa a fração de remanescente captada principalmente pelo fígado.

- k,0 $_{5,0}$ representa o desaparecimento dos ácidos graxos livres do compartimento extravascular. 


\section{Cálculo das taxas fracionais de remoção (TFR)}

As taxas fracionais de remoção (TFR) do ${ }^{3} \mathrm{H}-\mathrm{TG}$ e do ${ }^{14} \mathrm{C}-\mathrm{CE}$ medidas em $\min ^{-1}$ foram calculadas pelas fórmulas:

TFR ${ }^{14}$ C-CE: $\left(\mathrm{k}_{1,0} \times \mathrm{X} 2+\mathrm{k}_{2,0} \times \mathrm{X} 3\right) /(\mathrm{X} 2+\mathrm{X} 3)$

$\mathrm{X} 2: 1 / \mathrm{k}_{1,1}$

X3: $\mathrm{k}_{1,2} /\left(\mathrm{k}_{1,1} \times \mathrm{k}_{2,2}\right)$

TFR- ${ }^{3} H$-TG: $\left(\mathrm{k}_{3,0} \times \mathrm{X} 4+\mathrm{k}_{4,0} \times \mathrm{x}+\mathrm{k}_{5,0} \times \mathrm{x} 6\right) /(\mathrm{x} 4+\mathrm{x} 5+\times 6)$

$\mathrm{X} 4: 1 / \mathrm{k}_{3,3}$

$X 5: \mathrm{k}_{3,4} /\left(\mathrm{k}_{3,3} \times \mathrm{k}_{4,4}\right)$

$x 6: k_{3,4} \times k_{4,5} /(w 3 \times w 4 \times w 5)+k_{3,5} /(w 3 \times w 5)$

Taxa fracional de lipólise (TFL): $\left(\mathrm{k}_{3,5} \times \mathrm{X}_{4}+\mathrm{k}_{4,5} \times \mathrm{X5}\right) /(\mathrm{X} 4+\mathrm{X} 5)$

$\mathrm{X} 4: 1 / \mathrm{k}_{3,3}$

$\times 5: \mathrm{k}_{3,4} /\left(\mathrm{k}_{3,3} \times \mathrm{k}_{4,4}\right)$

\subsubsection{Considerações sobre proteção radiológica}

As doses de radioatividade injetadas nos participantes, em cada experimento, foram calculadas de acordo com as normas da "International Comission on Radiological Protection" 77. Para componentes orgânicos marcados com ${ }^{14} \mathrm{C}$ ou ${ }^{3} \mathrm{H}$, os valores de exposição anuais preconizados são $9 \times 10^{7}$ e $3 \times 10^{9} \mathrm{~Bq}$ respectivamente. No presente estudo, a dose injetada de 
${ }^{14} \mathrm{C}$ foi de $22,2 \times 10^{4}$ e para $0{ }^{3} \mathrm{H}$ de $44,4 \times 10^{4} \mathrm{~Bq}$, o equivalente à: $\left(44,4 \times 10^{4} \mathrm{~Bq} / 3 \times 10^{9} \mathrm{~Bq}\right) \times 50 \mathrm{mSv}=0,0075 \mathrm{mSv}$, dose bem abaixo do limite preconizado.

A dose equivalente incorporada no corpo inteiro em consequência da exposição aos lípides radioativos foi estimada em 0,04 mSv, conforme avaliado pelo método MIRD - Medical Internal Radiological Dosimetry ${ }^{78}$. Em conformidade com as normas de proteção radiológica da Comissão Nacional de Energia Nuclear de 1988, este valor é muito inferior ao máximo permitido, 50mSv.

O estudo tomográfico para avaliação do escore de cálcio correspondeu a uma exposição menor que 30 segundos aos raios $X$ (dose média de radiação aproximadas de 2,0 mSv ).

\subsection{Análises bioquímicas dos pacientes}

Todas as dosagens laboratoriais foram realizadas no Laboratório Central do HCFMUSP. As coletas de sangue foram realizadas no início dos estudos cinéticos após jejum de pelo menos 12 horas. Amostras de sangue foram colhidas em tubo de ensaio contendo EDTA $0,1 \%(10 \mu \mathrm{l} / \mathrm{ml}$ de sangue) e em tubo seco.

As concentrações de colesterol total, HDL-colesterol, triglicérides e glicemia presentes no plasma foram determinadas por reação bioquímica entre o reagente e o analito. Essa reação resultou em formação de cor que 
foi quantificada por método de espectrofotometria em equipamento modular da empresa Roche Diagnóstica.

O LDL-colesterol foi calculado pela fórmula de Friedewald. Quando o valor de triglicerídeos for maior que $400 \mathrm{mg} / \mathrm{dl}$, foi realizada determinação direta do LDL-colesterol, usando kit enzimático da Roche Diagnóstica. A lipoproteína (a), apo B e apo A-I foram determinadas por métodos enzimáticos padrão e as quantificações foram feitas por método de imunoturbidimetria em equipamento modular da empresa Roche Diagnóstica. Concentrações de proteína c reativa de alta sensibilidade (PCR-as) foram determinadas por método de nefelometria, em equipamento BN II (Dade Behring/Siemens), com valor de referência 0 a $5 \mathrm{mg} / \mathrm{dL}$. As determinações, lipoproteína (a), apo B e apo A-I e PCR-as, foram realizadas apenas nos portadores de HF.

\subsection{Determinação da mutação do receptor da LDL}

\subsubsection{Extração do DNA}

Foram coletados $10 \mathrm{~mL}$ de sangue periférico em tubo de hemograma contendo EDTA. A extração do DNA foi realizada como descrito por Miller e colaboradores ${ }^{79}$. O sangue foi hemolisado com tampão contendo $\mathrm{NH}_{4} \mathrm{Cl}$ 0,144M e NH4CO3 0,001M. Em seguida os leucócitos foram lisados (soluções Tris 0,01M, $\mathrm{NaCl}$ 0,4M, EDTA 0,002M pH 8,0 e EDTA 0,5M, 
SDS 10\% pH 8,0), o DNA foi precipitado (solução $\mathrm{NaCl} 6 \mathrm{M}$ ) e ressuspenso em TE (Tris-HCl 10mM, EDTA 1mM pH 8,0). A concentração da solução de DNA obtida foi determinada com leitura em espectrofotômetro a 260nm. A solução de DNA foi diluída em TE $(50 \mathrm{ng} / \mathrm{mL})$ para uso.

\subsubsection{Reação em cadeia da polimerase}

Os polimorfismos foram amplificados a partir do DNA genômico com auxílio do método de reação em cadeia da polimerase $(\mathrm{PCR})^{80}$. O protocolo desenvolvido por amostra consta de: $2 \mu \mathrm{L}$ de DNA $(20 \mathrm{ng} / \mathrm{ml})$ adicionados a $0,02 \mu \mathrm{L}$ da solução de desoxirribonucleotídeos trifosfatados $(10 \mathrm{mM}), 1 \mu \mathrm{L}$ de 10x Assay Buffer (Ultra Chem $\left.{ }^{\circledR}\right), 2 \mu \mathrm{L}$ de $\mathrm{MgCl} 2(10 \mathrm{mM}), 0,4 \mu \mathrm{L}$ de primer senso e $0,4 \mu \mathrm{L}$ de primer antisenso na concentração de $5 \mathrm{mM}$ e $0,06 \mu \mathrm{L}$ de enzima Taq polimerase (Easy Taq Invitrogen; 0,625 U) completando com água milliQ para totalizar um volume final de $10 \mu \mathrm{L}$. As reações de PCR foram realizadas em um termociclador (MiniCycler MJ Research), seguindo as condições especificadas para cada par de primers que foi utilizado. Em seguida as amostras das reações foram visualizadas em gel de agarose 1\%.

\subsubsection{Eletroforese em gel de agarose}

Os produtos de amplificação obtidos pela PCR foram analisados em gel de agarose $1,0 \%$. Para tanto, $1,0 \mathrm{~g}$ de agarose foi suspensa em $100 \mathrm{ml}$ de tampão tris-acetato-EDTA e fervida em forno de microondas até 
dissolução completa. Brometo de etídeo $25 \mathrm{mM}$ foi utilizado na proporção de $50 \mu \mathrm{l} / 100 \mathrm{~mL}$ de gel antes de sua polimerização. O tampão utilizado no preparo das amostras foi composto de glicerol 30\%, azul de bromofenol 0,05\% e xileno-cianol $0,05 \%$. A eletroforese foi realizada em uma cuba horizontal com tampão tris-acetato-EDTA com aplicação de aproximadamente 120 Volts. O marcador de peso molecular utilizado foi o DNA "Ladder" de $100 \mathrm{pb}$ (Gibco-BRL). Os fragmentos amplificados foram separados de acordo com o tamanho e visualizados pela exposição do gel à luz ultravioleta no equipamento EagleEye II (Stratagene).

\subsubsection{Sequenciamento automático}

Após a realização de um PCR comum para amplificação das amostras foram realizadas as seguintes etapas:

- Purificação das amostras amplificadas por PCR: A purificação foi realizada com o produto ExoSAP-IT (USB Corporation), o qual utiliza duas enzimas hidrolíticas, a Exonuclease I e a Shrimp Alkaline Phosphatase (SAP), para remover sobras de dNTPs e oligonucleotídeos. A Exonuclease I hidrolisa os oligonucleotídeos fita simples residuais e qualquer outra fita simples de DNA "estranha" produzida no PCR. A SAP hidrolisa os dNTPs remanescentes da mistura de PCR que poderiam interferir na reação de seqüenciamento. Adiciona-se a enzima diretamente no produto de PCR em qualquer volume, obedecendo-se sempre a proporção de 
$2 \mu \mathrm{l}$ de ExoSAP para $5 \mu \mathrm{l}$ de produto. Leva-se a mistura ao termociclador para ativação e ação das enzimas a $37^{\circ} \mathrm{C}$ por 15 minutos, seguido de um período de inativação a $85^{\circ} \mathrm{C}$ por 15 minutos. Assim, as amostras ficaram prontas para o sequenciamento.

- Sequenciamento do DNA: Todas as amostras purificadas foram, então, submetidas ao sequenciamento. O equipamento utilizado foi o ABI-3100 - Applied Biosystems em conjunto com o kit reagente $A B I$ PRISM BigDye terminator cycle sequencing ( $P E$ Applied Biosystems). Os primers utilizados para o sequenciamento estão descritos na tabela 1 . Amostras de $2,5 \mu$ los DNAs amplificados foram adicionadas a $2,5 \mu \mathrm{l}$ de primers senso ou antisenso (5pmol) juntamente com $1 \mu$ d do kit big dye terminator, $3 \mu l$ de DNA polimerase e tampão de reação 5x BigDye e $1 \mu$ l de água, totalizando um volume de $10 \mu \mathrm{l}$. Posteriormente, a mistura de reação foi purificada por precipitação com a adição de $80 \mu$ de Isopropanol (Merck) a 75-80\% em cada poço, a placa foi coberta com papel alumínio deixando-a em temperatura ambiente por 15 minutos. Após centrifugação (4000rpm por 30 min. a $4^{\circ} \mathrm{C}$ ), o etanol foi desprezado e $150 \mu$ l de etanol (70\%) sendo adicionados em cada poço, e em seguida as amostras foram novamente centrifugadas (4000rpm por 15 min. a $4^{\circ} \mathrm{C}$ ). A placa foi virada cuidadosamente para descartar o etanol. As amostras foram então, centrifugadas com a placa invertida a 4000rpm para a completa evaporação do etanol. As amostras de DNA foram 
desnaturadas a $96^{\circ} \mathrm{C}$ por 2 min. e 30 segundos. O precipitado de DNA foi ressuspenso com $10 \mu \mathrm{l}$ de formamida HI-DYE em cada poço. A placa foi homogeneizada e foi feita uma rápida centrifugação na placa. As amostras foram desnaturadas no termociclador por dois minutos e 30 segundos a $96^{\circ} \mathrm{C}$. Após a desnaturação, a placa foi acondicionada imediatamente em gelo por 3 a 5 minutos. As amostras foram depois injetadas no sequenciador $\mathrm{ABI}$ - 3100 conforme os parâmetros recomendados pelo fabricante.

Os genes sequenciados foram: LDL-R e APOB. Essa pesquisa foi realizada no Laboratório de Genética e Cardiologia Molecular do InCorHCFMUSP.

Foram identificadas mutações em 20 dos 36 pacientes com diagnóstico clínico de HF (ver tabela do anexo 1 para descrição das mesmas).

\subsection{Análise estatística}

O tamanho amostral deste estudo foi baseado em estudos de cinética previamente realizados no laboratório de metabolismo lipídico do InCor HCFMUSP utilizando-se a mesma metodologia ${ }^{37,39}$. A normalidade dos dados foi testada pelo método de Kolmogorov-Smirnov. As variáveis 
categóricas foram representadas por frequência absoluta (n) e relativa (\%) e as contínuas por média e desvio padrão ou medianas (intervalos) caso não apresentassem distribuição Gaussiana. A presença de associação entre variáveis categóricas foi verificada pelo teste do Qui-quadrado $(\chi 2)$ ou pelo teste exato de Fisher quando as suposições básicas do teste do quiquadrado não se encontravam satisfeitas. Já as variáveis contínuas foram comparadas entre os grupos por meio do teste $t$ de Student ou pelo teste de Mann-Whitney caso não apresentassem distribuição não Gaussiana. A análise ponto a ponto da curva de decaimento dos radioisótopos comparando-se os grupos HF e controle e dos HF com e sem CAC no decorrer do tempo foi realizada pelo método de ANOVA de medidas repetidas seguida pelo teste de múltiplas comparações de Tukey. Adotou-se o nível de significância de 0,05 ( $\alpha=5 \%)$.

\subsection{Implicações éticas}

Todos os sujeitos do estudo assinaram termo de consentimento informado. Este estudo foi aprovado pela CAPPESQ projeto número: $1067 / 06$ 
5 RESULTADOS 


\subsection{Comparação entre HF e controles normolipidêmicos}

A tabela 1 mostra as características clínicas dos pacientes portadores de HF e dos controles normolipidêmicos. Não foram encontradas diferenças quanto à idade, sexo, hipertensão e ao índice de massa corpórea (IMC) entre o grupo HF e controles. Contudo, o grupo de pacientes portadores de HF apresentou maior número de tabagistas $(p=0,03)$.

Tabela 1. Dados demográficos dos pacientes HF e controles

\begin{tabular}{lccc}
\hline & HF $(\mathbf{n}=\mathbf{3 6})$ & CONTROLES $(\mathbf{n = 5 0 )}$ & $\mathbf{P}$ \\
\hline Sexo masc. (\%) & $16(44)$ & $24(48)$ & 0,91 \\
Idade (anos) & $47 \pm 12$ & $47,8 \pm 14$ & 0,95 \\
IMC (Kg/m²) & $26 \pm 4$ & $25 \pm 3,5$ & 0,12 \\
HAS (\%) & $14(39)$ & $14(29)$ & 0,69 \\
Tabagismo (\%) & $5(14)$ & 0 & 0,03 \\
\hline
\end{tabular}

Legenda: IMC-índice de massa corpórea; HAS-hipertensão arterial sistêmica 
A tabela 2 mostra os dados laboratoriais dos pacientes $\mathrm{HF} \mathrm{e}$ controles. Foi observado maiores valores de colesterol total $(p<0,0001)$, LDL-colesterol $(p<0,0001)$ e triglicerídeos $(p<0,0001)$ no grupo de portadores de HF.

Tabela 2. Dados laboratoriais ( $\mathrm{mg} / \mathrm{dL}$ ) dos pacientes HF e controles

\begin{tabular}{lccc}
\hline & HF $(\mathbf{n = 3 6})$ & Controles $(\mathbf{n = 5 0 )}$ & $\mathbf{P}$ \\
\hline Colesterol total & $374 \pm 80$ & $196 \pm 30$ & $<0,0001$ \\
LDL-colesterol & $292 \pm 78$ & $124 \pm 30$ & $<0,0001$ \\
Triglicerídeos & $175 \pm 66$ & $118 \pm 45$ & $<0,0001$ \\
HDL-colesterol & $49 \pm 13$ & $50 \pm 14$ & 0,52 \\
Glicose & $94 \pm 8$ & $95 \pm 9$ & 0,64 \\
\hline
\end{tabular}

As figuras $3 \mathrm{a}$ e $3 \mathrm{~b}$ mostram respectivamente as curvas de decaimento do ${ }^{3} \mathrm{H}-\mathrm{TG}$ e ${ }^{14} \mathrm{C}-\mathrm{CE}$ nos portadores de HF e nos controles, já tabela 3 mostra os parâmetros da cinética dos quilomícrons artificiais. 


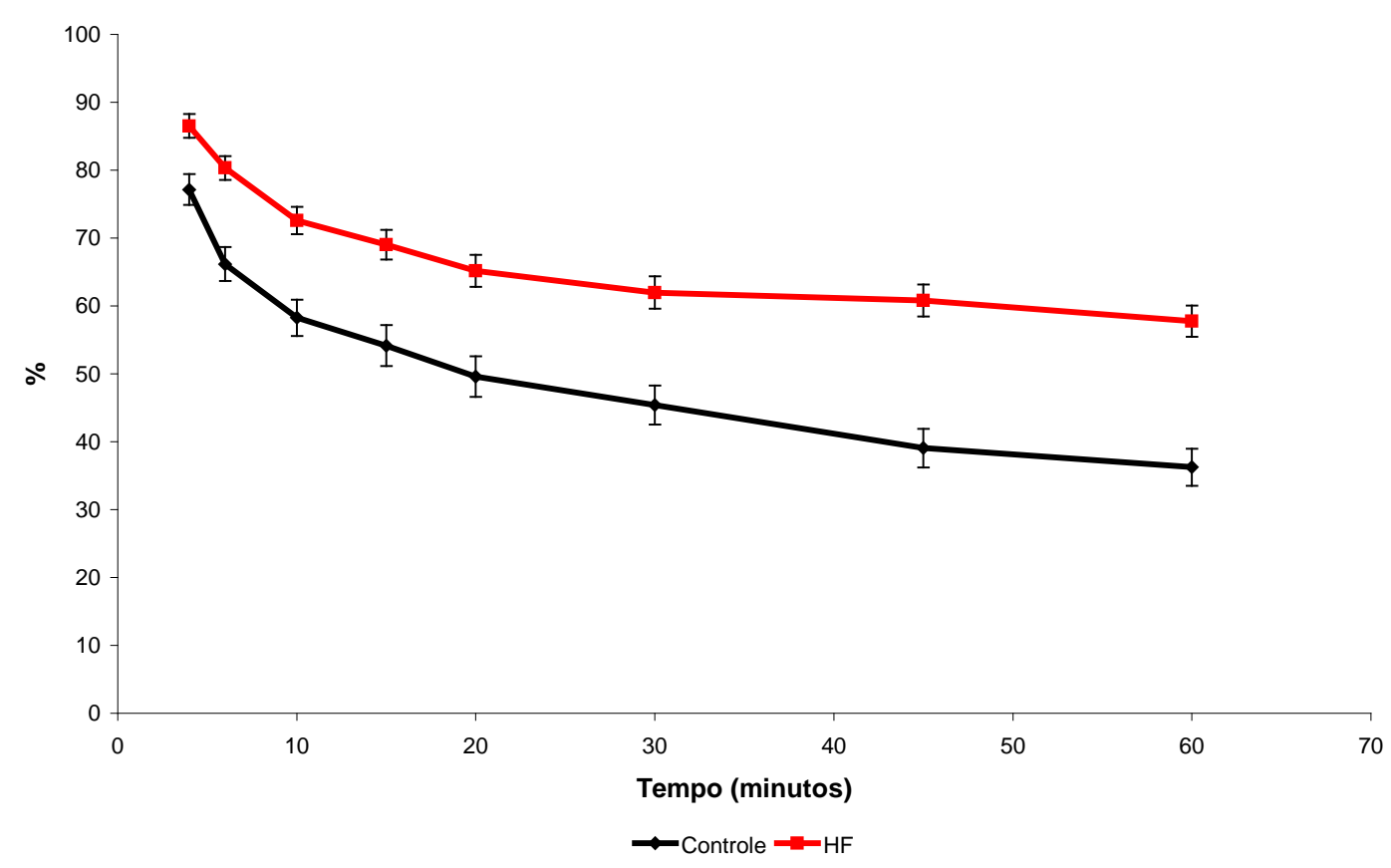

Legenda : Curva de decaimento do ${ }^{14} \mathrm{C}$-CE no tempo; no gráfico foi excluído o tempo zero que era similar nos dois grupos (100\%); $p<0,001$ para interação grupo tempo dos HF em relação aos controles.

Figura 3a. Curva de decaimento do ${ }^{14} \mathrm{C}$-CE dos portadores de HF e controles

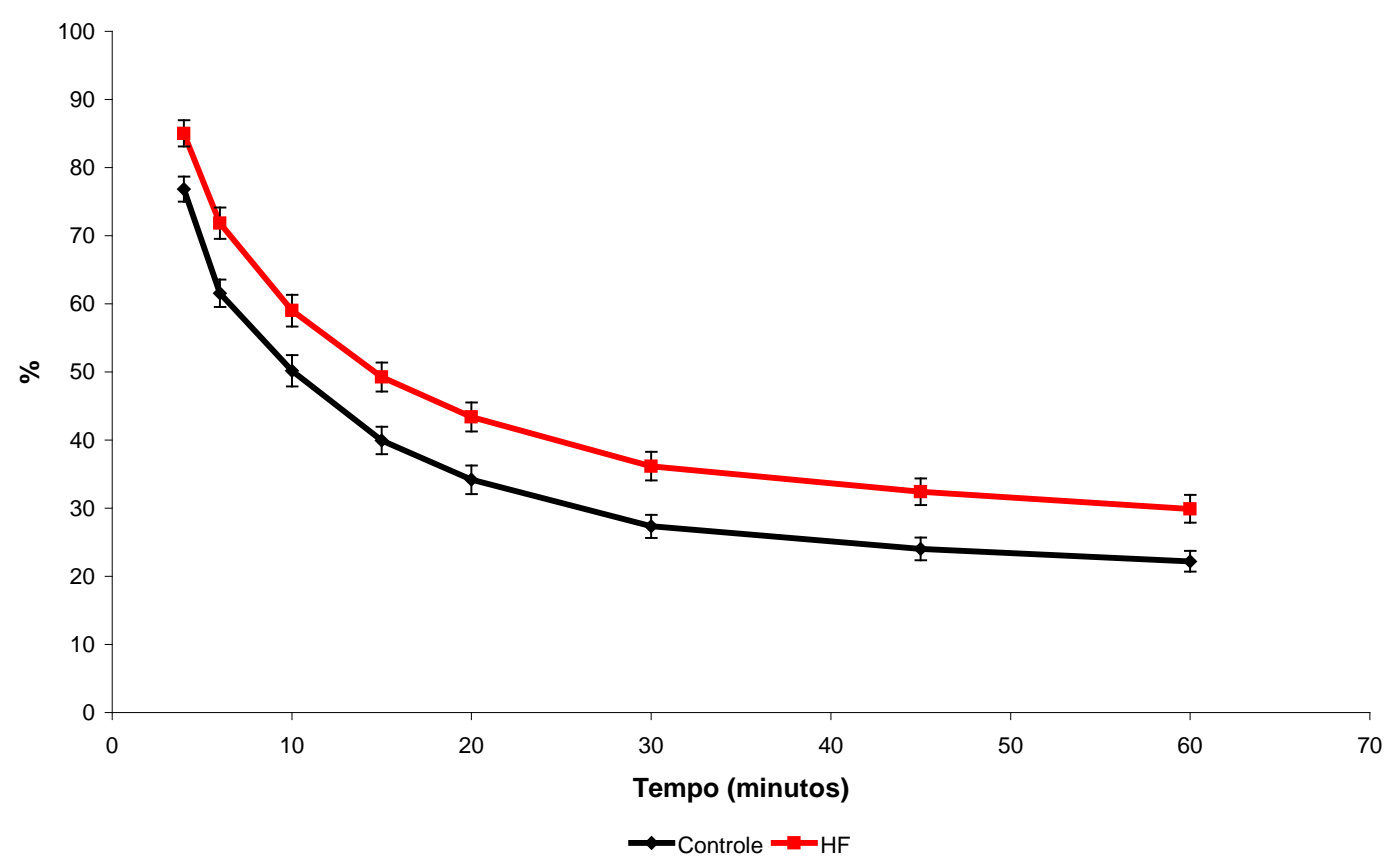

Legenda : Curva de decaimento do ${ }^{3} \mathrm{H}$-TG no tempo; no gráfico foi excluído o tempo zero que era similar nos dois grupos (100\%); $p=0,804$ para interação grupo tempo dos HF em relação aos controles.

Figura 3b. Curva de decaimento do ${ }^{3} \mathrm{H}-\mathrm{TG}$ dos portadores de HF e controles 
Ao analisarmos comportamento da curva de decaimento do ${ }^{14} \mathrm{C}$-CE observamos diferenças significativas entre os grupos $\mathrm{HF}$ e controles no decorrer do tempo $(p<0,001)$. Consequentemente as taxas fracionais de remoção de ${ }^{14} \mathrm{C}$-CE eram menores nos portadores de HF em relação aos controles respectivamente $0,0013\left(1,5 \cdot 10^{-9} ; 0,082\right) \min ^{-1}$ e $0,012\left(1,51 \cdot 10^{-9} ; 0,017\right) \min ^{-1}, \quad(p=0,001)$.

Ao analisarmos o comportamento da curva de decaimento do ${ }^{3} \mathrm{H}-\mathrm{TG}$ notamos que não houve diferença significativa dos grupos no decorrer do tempo ( $p=0,804)$. Da mesma forma não foram observadas diferenças quanto às taxas fracionais de remoção do ${ }^{3} \mathrm{H}$-TG $(p=0,26)$ e de lipólise $(p=0,198)$ entre os grupos.

$\mathrm{Na}$ análise das constantes de transferências $\left(k_{x, y}\right)$ foram observados valores menores de $k_{2,0}=k_{4,0}(p=0,005)$ e valores maiores de $k_{4,5}(p=0,0024)$ nos portadores HF em comparação aos controles. Não se observou diferenças nas outras constantes de transferências avaliadas. 
Tabela 3. Parâmetros da cinética plasmática dos quilomícrons artificiais dos portadores de hipercolesterolemia familiar (HF) e controles

\begin{tabular}{|c|c|c|c|}
\hline & $\operatorname{HF}(n: 36)$ & Controles(n:50) & $\mathbf{p}$ \\
\hline TFR ${ }^{14} \mathrm{C}-\mathrm{CE}$ & $0,0013\left(1,5 \cdot 10^{-9} ; 8 \cdot 10^{-2}\right)$ & $0,012\left(1,51.10^{-9} ; 0,17\right)$ & 0,001 \\
\hline TFR ${ }^{3} \mathrm{H}-\mathrm{TG}$ & $0,027\left(0,0004 ; 2,3 \cdot 10^{-2}\right)$ & $0,032(0,0004 ; 0,23)$ & 0,26 \\
\hline TFL & $0,019\left(3.10^{-4} ; 2,70\right)$ & $0,016(0,0002 ; 2,48)$ & 0,198 \\
\hline $\mathrm{k}_{1,0}=\mathrm{k}_{3,0}$ & $0,078\left(1.10^{-8} ; 0,55\right)$ & $0,073\left(1.10^{-8} ; 0,63\right)$ & 0,91 \\
\hline $\mathrm{k}_{2,0}=\mathrm{k}_{4,0}$ & $0,0007\left(1 \cdot 10^{-9} ; 0,43\right)$ & $0,005\left(1 \cdot 10^{-9} ; 9,0\right)$ & 0,005 \\
\hline $\mathrm{k}_{5,0}$ & $0,24(0,0024 ; 10)$ & $0,26(0,01 ; 10)$ & 0,62 \\
\hline $\mathrm{k}_{1,2=}=\mathrm{k}_{3,4}$ & $0,076(0,0086 ; 0,87)$ & $0,053(0,001 ; 9,7)$ & 0,075 \\
\hline $\mathrm{k}_{3,5}$ & $0,056(0,003 ; 0,36)$ & $0,056(0,01 ; 19,1)$ & 0,67 \\
\hline $\mathrm{k}_{4,5}$ & $0,007\left(1 \cdot 10^{-4} ; 8,79\right)$ & $0,0019\left(3,5 \cdot 10^{-5} ; 1,87\right)$ & 0,0024 \\
\hline
\end{tabular}

Legenda tabela 3: TFR-taxa fracional de remoção; TFL- taxa fracional de lipólise; $\mathrm{k}_{x, y}$ (constante de transferência do compartimento $\mathrm{x}$ para y) expressas em $\mathrm{min}^{-1}$. 


\subsection{Comparação dos grupos HF com ou sem CAC}

A tabela 4 mostra as características clínicas dos pacientes HF que apresentam ou não CAC. Não houve diferença significativa em relação à idade, sexo e fatores de risco para doença cardiovascular entre os grupos.

Tabela 4. Dados demográficos dos pacientes HF apresentando ou não CAC

\begin{tabular}{lccc}
\hline & Sem CAC (n=16) & Com CAC (n=20) & p \\
\hline Sexo masc.(\%) & $7(44)$ & $9(45)$ & 0,94 \\
Idade (anos) & $45,6 \pm 12$ & $49 \pm 11$ & 0,341 \\
IMC (Kg/m²) & $26 \pm 3,3$ & $26,7 \pm 4,6$ & 0,55 \\
HAS (\%) & $7(43)$ & $8(40)$ & 0,57 \\
Tabagismo (\%) & $2(13)$ & $3(15)$ & 0,072 \\
DAC precoce familiar (\%) & $10(63)$ & $13(65)$ & 0,11 \\
\hline
\end{tabular}

Legenda: CAC- calcificação da artéria coronária; IMC- índice de massa corpórea; HAS- hipertensão arterial sistêmica; DAC- doença arterial coronária.

A tabela 5 mostra os dados laboratoriais dos portadores de HF com e sem CAC. Os portadores de CAC apresentam concentrações maiores de colesterol total $(p=0,021)$, LDL-C $(p=0,048)$ e apo B $(p=0,024)$. Não houve diferença significativa entre os outros parâmetros avaliados. 
Tabela 5. Dados Laboratoriais dos pacientes HF com ou sem CAC

\begin{tabular}{lccc}
\hline & Sem CAC $(\mathbf{n = 1 6 )}$ & Com CAC $(\mathbf{n}=\mathbf{2 0})$ & $\mathbf{p}$ \\
\hline Colesterol total & $340 \pm 50$ & $401 \pm 89$ & 0,021 \\
HDL-colesterol & $48 \pm 13$ & $50 \pm 13$ & 0,70 \\
LDL-colesterol & $261 \pm 60$ & $318 \pm 82$ & 0,048 \\
Triglicerídeos & $181 \pm 74$ & $171 \pm 61$ & 0,75 \\
Glicose & $93 \pm 10$ & $95 \pm 8$ & 0,56 \\
Apo A-I & $132 \pm 45$ & $142 \pm 26$ & 0,59 \\
Apo B & $158 \pm 49$ & $197 \pm 47$ & 0,024 \\
Lp (a) & $81 \pm 77$ & $86 \pm 72$ & 0,90 \\
PCR-as & $3,6 \pm 3$ & $3,1 \pm 2$ & 0,97 \\
\hline
\end{tabular}

Legenda tabela 5: Lipides e apolipoproteinas em mg/dL; glicose em mg/dL; PCR-as em mg/L; PCR-as: proteína $C$ reativa de alta sensibilidade.

As figuras $4 \mathrm{a}$ e $4 \mathrm{~b}$ mostram respectivamente as curvas de decaimento do ${ }^{14} \mathrm{C}$-CE e ${ }^{3} \mathrm{H}$-TG nos portadores de HF com e sem CAC. Já a tabela 6 mostra a comparação dos parâmetros cinéticos de remoção do ${ }^{14} \mathrm{C}$-CE e ${ }^{3} \mathrm{H}-\mathrm{TG}$ entre HF com e sem CAC. 


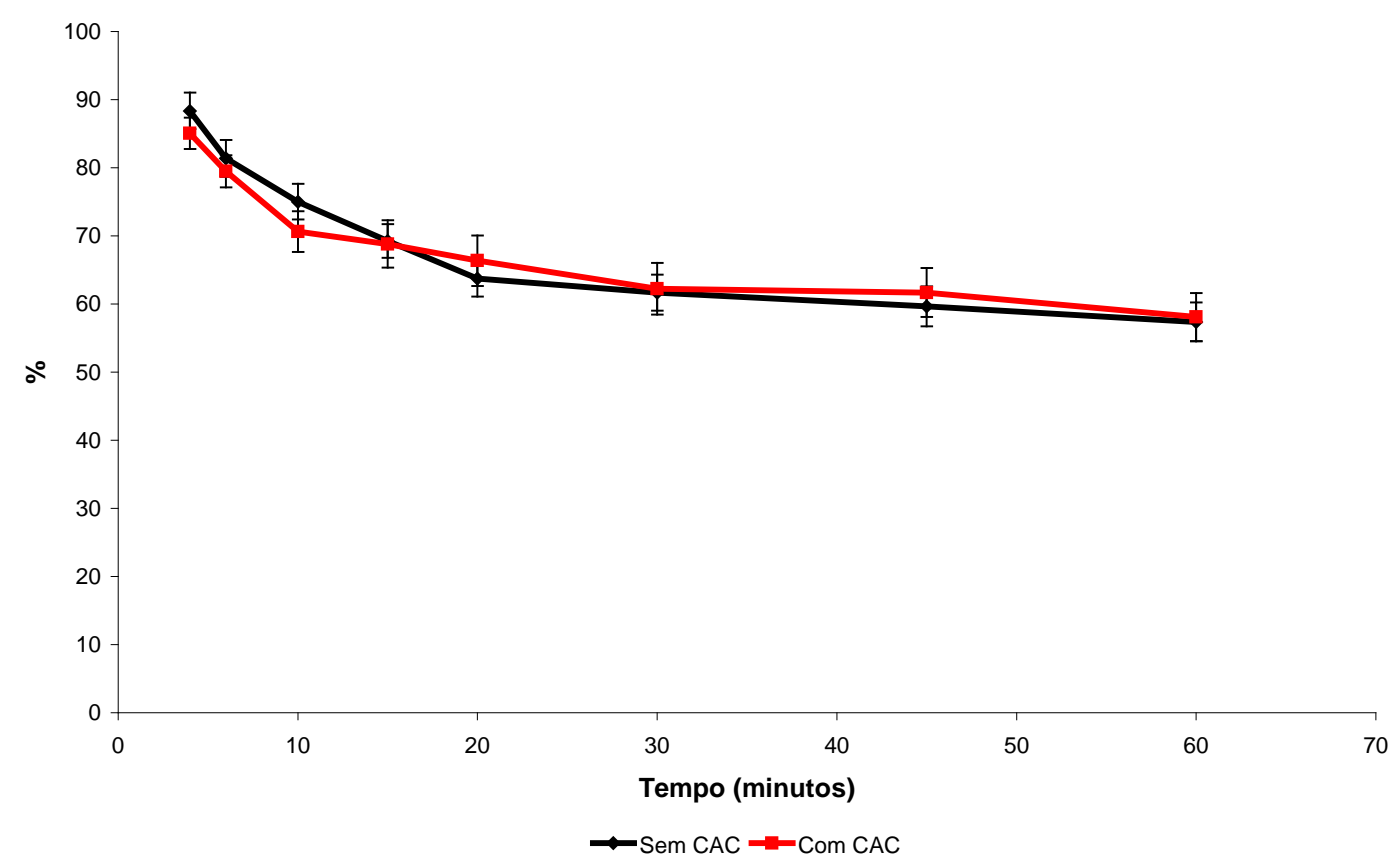

Legenda : Curva de decaimento do ${ }^{14} \mathrm{C}$-CE no tempo; no gráfico foi excluído o tempo zero que era similar nos dois grupos (100\%); $p=0,125$ para interação grupo tempo dos HF com e sem CAC.

Figura 4a. Curva de decaimento do ${ }^{14} \mathrm{C}-\mathrm{CE}$ dos portadores de HF com e sem CAC

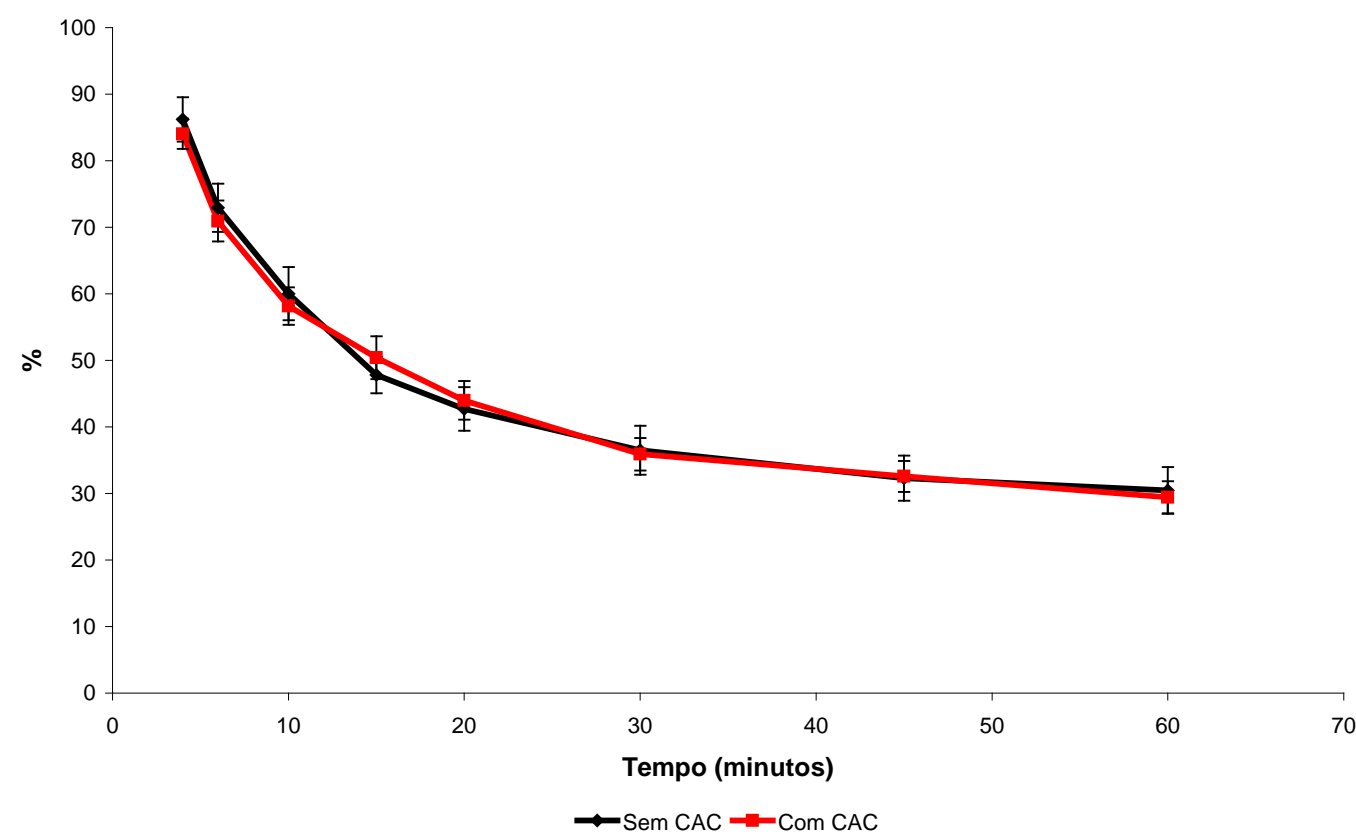

Legenda : Curva de decaimento do ${ }^{3} \mathrm{H}$-TG no tempo; no gráfico foi excluído o tempo zero que era similar nos dois grupos (100\%); $p=0,591$ para interação grupo tempo dos HF com e sem CAC.

Figura 4b. Curva de decaimento do ${ }^{3} \mathrm{H}-\mathrm{TG}$ dos portadores de HF com e sem CAC 
Não houve diferenças do comportamento das curvas de decaimento do ${ }^{14} \mathrm{C}$-CE e ${ }^{3} \mathrm{H}-\mathrm{TG}$ dos grupos com e sem CAC com o passar do tempo, $p=0,125$ e $p=0,591$, respectivamente. Da mesma forma não foram observadas diferenças nas taxas fracionais de remoção de ${ }^{14} \mathrm{C}-\mathrm{CE}(p=0,67)$, ${ }^{3} \mathrm{H}$-TG $(p=0,79)$ e de lipólise $(p=0,59)$ entre os portadores ou não de CAC. As constantes de transferência $\left(k_{x, y}\right)$, não diferiram entre os grupos estudados, p >0,05 para todas as análises.

Tabela 6. Parâmetros da cinética plasmática dos quilomícrons artificiais dos portadores de hipercolesterolemia familiar (HF) com e sem CAC

\begin{tabular}{llll}
\hline & \multicolumn{1}{c}{ Sem CAC $(\mathbf{n = 1 6})$} & \multicolumn{1}{c}{ Com CAC $(\mathbf{n = 2 0})$} & $\mathbf{P}$ \\
\hline TFR ${ }^{14} \mathrm{C}$-CE & $0,0007\left(1,47.10^{-9} ; 0,082\right)$ & $0,0013\left(1,6.10^{-9} ; 0,038\right)$ & 0,67 \\
TFR ${ }^{3} \mathrm{H}$-TG & $0,025(0,0004 ; 0,075)$ & $0,029(0,009 ; 0,23)$ & 0,79 \\
TFL & $0,018(0,0002 ; 0,156)$ & $0,021(0,0004 ; 2,67)$ & 0,60 \\
$\mathrm{k}_{1,0=} \mathrm{k}_{3,0}$ & $0,080(0,03 ; 0,55)$ & $0,075\left(1.10^{-8} ; 0,50\right)$ & 0,48 \\
$\mathrm{k}_{2,0=} \mathrm{k}_{4,0}$ & $0,0003\left(1.10^{-9} ; 0,04\right)$ & $0,0007\left(1.10^{-9} ; 0,037\right)$ & 0,88 \\
$\mathrm{k}_{5,0}$ & $0,21(0,01 ; 10)$ & $0,28(0,0023 ; 10)$ & 0,68 \\
$\mathrm{k}_{1,2=} \mathrm{k}_{3,4}$ & $0,094(0,027 ; 0,46)$ & $0,0750(0,008 ; 0,87)$ & 0,71 \\
$\mathrm{k}_{3,5}$ & $0,070(0,01 ; 0,36)$ & $0,04(0,003 ; 0,35)$ & 0,19 \\
$\mathrm{k}_{4,5}$ & $0,0080\left(1.10^{-4} ; 4,6\right)$ & $0,0050\left(1.10^{-4} ; 8,79\right)$ & 0,31 \\
\hline
\end{tabular}

Legenda tabela 6: TFR-taxa fracional de remoção; TFL- taxa fracional de lipólise; $\mathrm{k}_{\mathrm{x}, \mathrm{y}}$ (constante de transferência do compartimento $\mathrm{x}$ para y) expressas em $\mathrm{min}^{-1}$. 
6 DISCUSSÃO 
Este estudo observou diferenças significativas no comportamento da cinética plasmática dos quilomícrons artificiais entre portadores de HF heterozigótica, diagnosticada por critérios clínicos e por genotipagem, e indivíduos normolipidêmicos. Entretanto, essas alterações não se associaram numa análise transversal com a presença de aterosclerose subclínica representada pela CAC.

\section{Comparação da cinética dos quilomícrons artificiais entre HF e normolipidêmicos}

No presente estudo foi verificada redução significativa na remoção do remanescente dos quilomícrons nos portadores de HF em relação aos controles. Nos primeiros a TFR do ${ }^{14} \mathrm{C}$-CE foi cerca de 10 vezes menor em relação aos últimos. O modelo de análise compartimental utilizado nos permitiu demonstrar que esses defeitos decorrem da diminuição das taxas de transferência do compartimento plasmático para o fígado $\left(k_{2}, 0=k_{4}, 0\right)$ expressando a fase lenta da curva de decaimento do ${ }^{14} \mathrm{C}-\mathrm{CE}$. Por outro lado, não foram encontradas diferenças significativas entre os grupos respectivamente na remoção dos triglicérides e na taxa de lipólise das partículas da emulsão. Embora não tenha havido diferença nas TFR do ${ }^{3} \mathrm{H}-\mathrm{TG}$ entre os grupos foi encontrado aumento significante na taxa de transferência do compartimento 4 para $5\left(k_{4,5}\right)$ nos HF em relação aos controles. $O k_{4,5}$ 
representa em nosso modelo teórico a remoção do ácido graxo livre do remanescente de quilomícron para o compartimento extravascular. Isso pode ser consequente do maior tempo de exposição dos triglicérides dos remanescentes de quilomícrons à lipase lipoprotéica já que sua taxa de remoção do plasma representada pelos $k_{2,0}$ e $k_{4,0}$ é aproximadamente 10 vezes menor nos HF em relação aos controles. É importante enfatizar que embora portadores de HF possam ter elevação discreta dos valores de triglicérides de jejum no plasma em relação aos controles, como encontrado em nossos pacientes, esta é atribuída geralmente à hiperprodução de VLDL pelo fígado e não a defeitos na sua lipólise ${ }^{81}$.

Classicamente a HF é caracterizada por defeitos na função ou expressão do receptor da LDL, embora mais raramente defeitos na apo B100 e no aumento de função da PCSK-9 possam causar fenótipo similar ${ }^{4,5}$. Defeitos na expressão do receptor da LDL classicamente levam aos elevados valores de LDL-C no plasma dos portadores de HF, já que a LDL não é removida de forma adequada pelo fígado. Os remanescentes de quilomícrons por sua vez poderiam se acumular no plasma de portadores de HF já que o receptor da LDL liga-se tanto a apo B100 das VLDL, seus remanescentes e LDL, quanto à apo E que é carregada na superfície dos quilomícrons e seus remanescentes ${ }^{32-34}$. É importante enfatizar que a afinidade do LDLR pela apo E é cerca de cinco vezes o da afinidade do mesmo pela apo B100 ${ }^{32,33}$.

As emulsões de quilomícrons artificiais assemelham-se em tamanho e composição a pequenos quilomícrons e são removidas pelo fígado graças à 
presença da apo E em sua superfície ${ }^{42}$. Vários estudos realizados pelo grupo do Prof. Raul Maranhão in InCor-HCFMUSP e na Faculdade de Ciências Farmacêuticas da USP demonstraram que as emulsões são úteis para avaliar a função do receptor da $\operatorname{LDL}^{37,38,43,44}$. Previamente Sposito et al. ${ }^{43}$ encontraram relação inversa entre as TFR do ${ }^{14} \mathrm{C}-\mathrm{CE}$ com concentrações de LDL-C e apo B, marcadores indiretos da função do receptor da LDL, em portadores de doença coronária crônica ${ }^{43}$. Já manobras que aumentam a expressão do receptor da LDL como o uso de estatinas incrementam a TFR do ${ }^{14} \mathrm{C}$-CE em indivíduos portadores de DAC ou de dislipidemia aterogênica ${ }^{38,44}$. De fato o uso de doses mais elevadas de atorvastatina (40 mg) nestes indivíduos aumentou significativamente a remoção dos remanescentes de quilomícrons (diminuição em 73\% nos tempos de permanência do remanescente no plasma) em comparação ao placebo (sem efeito) e a dose de $10 \mathrm{mg}$. Esta por sua vez havia diminuído em 50\% o tempo de permanência dos remanescentes no plasma. Esses resultados sugerem que um maior efeito sobre a expressão do receptor da LDL com a dose de $40 \mathrm{mg}$ consequentemente levaram a uma maior remoção plasmática dos remanescentes de quilomícrons. Mais recentemente Mangili et al. (dados não publicados) encontraram que o uso da ezetimiba, um bloqueador de absorção do colesterol pelo intestino, em forma isolada ou em associação com a sinvastatina aumentam também a TFR do ${ }^{14} \mathrm{C}$-CE. A ezetimiba embora atue preferencialmente no intestino ligando-se ao receptor NPC1-L1, leva a aumento do RNA mensageiro do receptor da LDL no fígado ${ }^{82}$. 


\section{Estudos do metabolismo de quilomícrons em modelos animais de HF}

Há controvérsias na literatura se realmente ocorrem defeitos no catabolismo de quilomícrons e seus remanescentes em portadores de $\mathrm{HF}^{45-47,49,50}$. Isso decorre, como citado anteriormente, do fato destes últimos serem removidos não apenas pelo receptor B e E mas, principalmente pelo receptor específico LRP, quando entram no espaço de Disse Bowler et al. ${ }^{83}$ encontraram graves defeitos na remoção das emulsões de quilomícrons artificiais, similares as utilizadas em nosso estudo, em coelhos Watanabe, um clássico modelo animal de HF. A redução da remoção dos remanescentes e da lipólise dos quilomícrons foi encontrada tanto em animais heterozigóticos como homozigotos para a expressão do receptor da LDL. Da mesma forma Hussain et al. ${ }^{84}$ encontraram diminuição na remoção de quilomícrons da linfa em coelhos normais que foram alimentados com colesterol, uma manobra que reduz a expressão do receptor da LDL, e em coelhos Watanabe. Ambos os grupos de animais apresentaram diminuição da quantidade do receptor $\mathrm{B}, \mathrm{E}$ no fígado em relação aos coelhos controles. Choi et al. ${ }^{51}$ mostraram diminuição da remoção dos quilomícrons em animais tratados com anticorpos contra o receptor da LDL. Por outro lado, Kita et al. $^{48}$ não encontraram defeitos na remoção dos quilomícrons da linfa em coelhos Watanabe. Herz et al. ${ }^{85}$ estudando camundongos "knockout" para o receptor da LDL, aonde o receptor LRP é dominante, também não encontraram redução do clareamento plasmático dos remanescentes de quilomícrons. 


\section{Estudos do metabolismo de quilomícrons em portadores de HF}

A controvérsia originada nos modelos animais estende-se para estudos em humanos. Isso decorre muitas vezes de heterogeneidade das populações estudadas e dos métodos de avaliação utilizados nesses estudos ${ }^{45,50}$. Rubinsztein et al. ${ }^{45}$ avaliaram o metabolismo pós-prandial das lipoproteínas ricas em triglicérides pelo método do retinil-palmitato e não encontraram alterações em 5 indivíduos HF homozigóticos . Da mesma forma, Eriksson et al. $^{86}$ utilizando o mesmo método não encontraram diferenças na lipemia pós prandial entre 9 indivíduos HF heterozigotos e 23 controles. Por outro lado, Mamo et al. ${ }^{46}$ encontraram acúmulo tanto do retinilpalmitato quando da apo B48,a principal apo estrutural dos quilomícrons e remanescentes, em HF homozigotos japoneses. Nesses indivíduos a ligação "in vitro" e captação dos remanescentes de quilomícrons marcados com $\mathrm{I}^{-125}$ por fibroblastos estava diminuída quando comparada aos indivíduos normolipidêmicos. Da mesma forma, Cabezas et al. $^{47}$ encontraram diminuição no clearance dos remanescentes medido pela cinética do retinil-palmitato em 5 HF heterozigotos em relação a 9 controles . O mesmo grupo de investigadores encontrou aumento na lipemia pósprandial de 7 portadores de HF em relação a controles utilizando o ensaio de medida do colesterol das lipoproteínas remanescentes (RLP-C). No mesmo estudo o uso de $80 \mathrm{mg}$ de sinvastatina, medicamento que sabidamente aumenta a expressão hepática do receptor da $\operatorname{LDL}{ }^{87}$, reduziu a concentração das RLP-C mas não diminuiu a lipemia pós-prandial. 
Controvérsias existem também quando se mede as concentrações de apo B48 em portadores de HF. Dane-Stewart et al. ${ }^{88}$ encontraram aumento nas concentrações em jejum de apo B100, apo B48 e RLP-C em 15 HF heterozigóticos em comparação a controles . Tremblay et al. ${ }^{50}$ encontraram aumento no "pool" de apo B48 em portadores de HF heterozigótica portadores de mesma mutação "nula" do receptor da LDL. Entretanto o estudo cinético com isótopos estáveis nesses indivíduos não encontrou diminuição da remoção hepática dessa apolipoproteína, mas sim aumento da produção intestinal da mesma. Ou seja, portadores de HF poderiam tem aumento de quilomícrons no plasma mais por um problema de produção elevada do que por diminuição da expressão do receptor da LDL.

A controvérsia se há realmente defeito na remoção dos quilomícrons e remanescentes em portadores de HF persiste quando se avalia estudos que utilizaram a emulsão de quilomícrons artificiais. Diferentemente de nossos resultados Watts et al. ${ }^{49}$ não encontraram diminuição das TFR do remanescente de quilomícron artificial em 10 HF homozigotos e 15 heterozigotos em relação aos controles. Contudo apesar de utilizarem a mesma emulsão de nosso estudo o método de análise empregado pelos autores foi diferente do nosso protocolo de pesquisa. A emulsão de quilomícrons artificiais foi marcada no caso com isótopos estáveis e foi medida a eliminação do ${ }^{13} \mathrm{C}$ pela via respiratória por um período de 24 horas. Nesse período, várias refeições foram consumidas pelos sujeitos da pesquisa diferentemente de nosso estudo realizado em 60 minutos, aonde 
foram feitas coletas de amostras de sangue e aonde os sujeitos da pesquisa permaneceram em jejum e em repouso durante todo o experimento. Previamente Maranhão et al. $^{37}$ mostraram importante lentificação da remoção dos quilomícrons artificiais quando compararam estudos realizados em jejum e no período pós-prandial . Os próprios autores reconheceram que o teste respiratório não é uma medida direta do clareamento plasmático dos remanescentes, sendo que repouso absoluto por 24 horas seria condição ideal para realização desse estudo, fato que não ocorreu. Um achado paradoxal do estudo de Watts et al., atribuído pelos autores ao baixo consumo de ácidos graxos nos pacientes HF homozigóticos, foi que a constante de transferência que equivale ao $k_{2,0}$, ou seja, justamente aonde foi encontrada diminuição da remoção nosso modelo compartimental, encontrava-se aumentada em relação aos controles e aos heterozigotos. Da mesma forma nos homozigóticos aonde deveríamos ter maiores defeitos de remoção dos remanescentes apresentaram as menores áreas sob a curva de enriquecimento do ${ }^{13} \mathrm{C}-\mathrm{CO} 2$.

Em recente revisão sobre o metabolismo de lipoproteínas ricas em triglicérides em portadores de HF Kolovou et al. ${ }^{81}$ sumarizam que embora haja controvérsias, predominam na literatura estudos que indicam defeitos no metabolismo de quilomícrons e remanescentes em portadores de HF. As diferenças dos resultados entre os diversos estudos poderiam ser explicadas por heterogeneidade nos pacientes estudados e nos métodos utilizados. É possível que o tipo de mutação do receptor da LDL, por exemplo, mutações nulas vs. defeituosas ${ }^{89,90}$, presença ou não de 
resistência à insulina ${ }^{91}$, genótipo da apolipoproteína $\mathrm{E}^{92}$, produção exagerada ou não de VLDL pelo fígado ${ }^{81}$, além de outros fatores desconhecidos possam influenciar nos resultados encontrados. Da mesma forma o teste predominantemente utilizado do retinil-palmitato nos diversos estudos, sofre influências do tipo de dieta ofertado ${ }^{93}$, do tempo de esvaziamento gástrico ${ }^{92}$, da absorção intestinal e da dificuldade de separação das diversas lipoproteínas em triglicérides medidas no período pós-prandial ${ }^{94}$.

Em nossa opinião a grande vantagem do método utilizado neste estudo é que é possível avaliar a via de remoção das lipoproteínas ricas em triglicérides, no caso dos quilomícrons e remanescentes, de forma "limpa", simples e de fácil execução sem haver interferências dos diversos fatores que influenciam o período pós-prandial. Além disso, outro ponto forte do método utilizado em neste estudo é que a cinética do ${ }^{14} \mathrm{C}-\mathrm{CE}$ correlaciona-se não apenas com os valores de LDL-C, mas também com manobras que modificam a expressão do receptor da LDL, como o uso de estatinas ${ }^{38,44}$ e ezetimiba (Mangili et al. dados não publicados) que afetam o catabolismo plasmático da emulsão dos quilomícrons artificiais. Nossos resultados mostram clara diminuição na remoção dos remanescentes de quilomícrons nos portadores de HF sem, contudo, haver alteração no mecanismo relacionados com a remoção dos triglicérides dessas partículas. 
Ausência da associação dos defeitos da remoção plasmática dos quilomícrons artificiais com a presença de aterosclerose subclínica em portadores de HF

Estudos prévios realizados no InCor pelo grupo do Prof. Raul Maranhão encontraram defeitos na remoção dos quilomícrons artificiais em portadores de DAC diagnosticada por critérios clínicos e comprovada por angiografia coronária invasiva ${ }^{37,40,41}$. A remoção do ${ }^{14} \mathrm{C}-\mathrm{CE}$ e a lipólise dos triglicérides correlacionaram-se de forma independente, após análise multivariada, com a gravidade da DAC medida pelo escore angiográfico de Gensini $^{40}$. Mais ainda a alterações na lipólise dessas lipoproteínas associaram-se de forma prospectiva e independente com o agravamento dos sintomas da angina do peito nesses indivíduos ${ }^{41}$. É importante enfatizar que esses indivíduos não apresentavam critérios clínicos e laboratoriais para a HF.

Embora neste estudo observássemos diferenças significativas na cinética dos remanescentes dos quilomícrons entre portadores de HF e indivíduos normolipidêmicos, esta não se associou com a presença da CAC na HF. A ausência de associação entre o grave distúrbio de remoção do ${ }^{14} \mathrm{C}-\mathrm{CE}$ dos portadores com a CAC poderia ser explicado da seguinte forma:

1- Possível falta de contribuição do distúrbio de remoção dos quilomícrons e remanescentes para a aterogênese em uma situação na qual as concentrações de LDL-C são extremamente elevadas. Embora não tenham estudado o metabolismo dos quilomícrons e remanescentes, Martinez et al. ${ }^{72}$ e Miname et al. ${ }^{71}$ 
observaram que apenas a idade avançada e as concentrações de LDL-C se associaram de forma independente com a presença e gravidade da CAC em portadores de HF.

2- Maranhão et al. ${ }^{37}$ e Sposito et al. ${ }^{41}$ avaliaram pacientes com DAC avançada, com faixa etária mais elevada (cerca de 60 anos contra a média de 45 anos em nosso estudo), sem hipercolesterolemia grave, sendo indivíduos sintomáticos e com obstruções visualizadas a angiografia coronária invasiva . Ou seja, indivíduos que apresentavam grau bem mais avançado de aterosclerose do que nossos portadores de HF totalmente assintomáticos para a DAC. Essa diferença no tipo de população estudada poderia explicar os resultados. É possível que em indivíduos com valores mais baixos de LDL-C, distúrbios do metabolismo dos quilomícrons e das outras lipoproteínas ricas em triglicérides possam ter maior papel na termogênese ${ }^{95,96}$.

3- A natureza transversal de nosso estudo não permite inferir causalidade do distúrbio do metabolismo dos quilomícrons com a DAC, sendo que somente um estudo prospectivo poderia realmente comprovar esta hipótese. De fato não há evidências na literatura que distúrbios do metabolismo dos quilomícrons se associam com a DAC em portadores de HF diferentemente do que ocorre com a população geral ${ }^{95,96}$.

4- Finalmente um poder limitado do teste estatístico para mostrar associação já que as TFR do ${ }^{14}$ C-CE são extremamente lentas 
nos portadores de HF. Um cálculo "a posteriori" da nossa amostra utilizando pacientes com DAC clínica e sem HF mostrou que precisaríamos de pelo menos 35 pacientes para cada grupo de portadores de HF para mostrar uma diferença significativa nas TFR do ${ }^{14} \mathrm{C}$-CE considerando-se um poder estatístico de $80 \%$ para uma significância de 5\%.

Finalmente estudos prospectivos e com grande número amostral são necessários para demonstrar que as alterações da remoção plasmática dos quilomícrons encontradas nesse estudo realmente irão contribuir para agravamento do processo de aterosclerose em portadores de HF. 
7 CONCLUSÃO 
- Os portadores de HF apresentaram diminuição significativa das taxas fracionais de remoção plasmáticas dos remanescentes de quilomícrons $\left({ }^{14} \mathrm{C}-\mathrm{CE}\right)$ artificiais quando comparados aos controles normolipidêmicos.

- Isso foi decorrente de redução das taxas de transferências da fase lenta da curva de decaimento do ${ }^{14} \mathrm{C}-\mathrm{CE}$.

- Não houve diferenças na remoção do ${ }^{3} \mathrm{H}-\mathrm{TG}$ ou da taxa fracional de lipólise dos HF em relação aos controles.

- Os parâmetros cinéticos da emulsão dos quilomícrons artificiais não diferiram nos portadores de HF com e sem CAC. 
8 ANEXOS 
Anexo 1. Tabela do diagnóstico genético dos pacientes portadores de HF

\begin{tabular}{|c|c|c|}
\hline Pacientes & Diagnóstico & localização da mutação \\
\hline 1 & N564H (Asn564His) E Val800-Leu802del & mutação exon 11 e 17 \\
\hline 2 & sem mutação LDL e Apo B & \\
\hline 3 & Mutação P685L & mutação exon 14 \\
\hline 4 & D301G (Asp301Gly) & mutação exon 6 \\
\hline 5 & sem mutação LDL e Apo B & \\
\hline 6 & C681x $($ Cys681*) & mutação exon 14 \\
\hline 7 & Val806GlyfsX11 & mutação exon 17 \\
\hline 8 & Val806GlyfsX11 & mutação exon 17 \\
\hline 9 & sem mutação LDL e Apo B & \\
\hline 10 & sem mutação LDL e Apo B & \\
\hline 11 & Val806GlyfsX11 & mutação exon 17 \\
\hline 12 & Asp224_Ser226dup & mutação exon 4 \\
\hline 13 & sem mutação LDL e Apo B & \\
\hline 14 & sem mutação LDL e Apo B & \\
\hline 15 & sem mutação LDL e Apo B & \\
\hline 16 & sem mutação LDL e Apo B & \\
\hline 17 & Asp224_Ser226dup & mutação exon 4 \\
\hline 18 & Mutação Cys681X & mutação exon 14 \\
\hline 19 & Glu317GlyfsX15 & mutação exon 7 \\
\hline 20 & sem mutação LDL e Apo B & \\
\hline 21 & sem mutação LDL e Apo B & \\
\hline 22 & sem mutação LDL e Apo B & \\
\hline 23 & S326C (Ser326Cys) & mutação exon 7 \\
\hline 24 & Mutação P685L & mutaçaõ exon 14 \\
\hline 25 & sem mutação LDL e Apo B & \\
\hline 26 & E228K (Glu228Lys) & mutação exon 4 \\
\hline 27 & C276W (Cys276Trp) & mutação exon 6 \\
\hline 28 & sem mutação LDL e Apo B & \\
\hline 29 & sem mutação LDL e Apo B & \\
\hline 30 & R350X (Arg350*) & mutação exon 7 \\
\hline 31 & His837ThrfsX23 & mutação exon 17 \\
\hline 32 & R595W (Arg595Trp) & mutação exon 12 \\
\hline 33 & sem mutação LDL e Apo B & \\
\hline 34 & sem mutação LDL e Apo B & \\
\hline 35 & Gly373Asp & mutação exon 11 \\
\hline 36 & Phe629TyrfsX16 & mutação exon 13 \\
\hline
\end{tabular}


Anexo 2. Tabela com dados clínicos e laboratoriais do grupo controle

\begin{tabular}{|c|c|c|c|c|c|c|c|c|}
\hline Paciente & Peso(Kg) & Altura(m) & IMC $\left(\mathrm{Kg} / \mathrm{m}^{2}\right)$ & Idade & CT & HDL & LDL & TG \\
\hline 1 & 70 & 1,64 & 26,02 & 31 & 218 & 37 & 157 & 119 \\
\hline 2 & 75 & 1,47 & 34,7 & 66 & 217 & - & - & 174 \\
\hline 3 & 83 & 1,85 & 24,25 & 42 & 220 & 40 & 154 & 129 \\
\hline 4 & 56 & 1,57 & 22,71 & 36 & 181 & 44 & 128 & 46 \\
\hline 5 & 83 & 1,7 & 28,71 & 33 & 240 & 30 & 171 & 202 \\
\hline 6 & 64 & 1,58 & 25,63 & 56 & 144 & 92 & 92 & 59 \\
\hline 7 & 78 & 1,69 & 27,3 & 39 & 195 & 53 & 124 & 91 \\
\hline 8 & 58 & 1,6 & 22,65 & 51 & 170 & 69 & 90 & 56 \\
\hline 9 & 85 & 1,7 & 29,41 & 66 & 195 & 69 & 113 & 67 \\
\hline 10 & 60 & 1,62 & 22,86 & 27 & 172 & 70 & 90 & 115 \\
\hline 11 & 74 & 1,75 & 24,16 & 41 & 157 & 34 & 91 & 159 \\
\hline 12 & 61 & 1,7 & 21,1 & 24 & 129 & 54 & 66 & 43 \\
\hline 13 & 64 & 1,6 & 25 & 72 & 207 & 65 & 116 & 128 \\
\hline 14 & 78 & 1,73 & 26,06 & 38 & 221 & 42 & 158 & 107 \\
\hline 15 & 56 & 1,55 & 23,31 & 35 & 178 & 61 & 104 & 65 \\
\hline 16 & 70 & 1,75 & 22,86 & 40 & 206 & 66 & 103 & 136 \\
\hline 17 & 68 & 1,7 & 23,53 & 61 & 233 & 28 & 163 & 210 \\
\hline 18 & 60 & 1,6 & 23,44 & 68 & 183 & 74 & 96 & 65 \\
\hline 19 & 81 & 1,72 & 27,38 & 54 & 181 & 32 & 126 & 115 \\
\hline 20 & 63 & 1,71 & 21,55 & 63 & 181 & 43 & 122 & 79 \\
\hline 21 & 75 & 1,65 & 27,55 & 69 & 209 & 44 & 146 & 94 \\
\hline 22 & 67 & 1,7 & 23,18 & 26 & 108 & 44 & 54 & 49 \\
\hline 23 & 46 & 1,6 & 17,97 & 23 & 200 & 75 & 113 & 59 \\
\hline 24 & 79 & 1,78 & 24,93 & 38 & 182 & 45 & 115 & 111 \\
\hline 25 & 55 & 1,6 & 21,48 & 38 & 181 & 52 & 94 & 174 \\
\hline 26 & 85 & 1,69 & 29,76 & 67 & 221 & 37 & 156 & 138 \\
\hline 27 & 59 & 1,65 & 21,67 & 61 & 229 & 44 & 229 & 115 \\
\hline 28 & 65 & 1,63 & 24,46 & 50 & 228 & 52 & 144 & 161 \\
\hline 29 & 75 & 1,7 & 25,95 & 41 & 176 & 35 & 118 & 117 \\
\hline 30 & 66 & 1,55 & 27,47 & 65 & 222 & 33 & 161 & 138 \\
\hline 31 & 66 & 1,6 & 25,78 & 65 & 228 & 48 & 147 & 163 \\
\hline 32 & 71 & 1,76 & 22,92 & 64 & 237 & - & - & 127 \\
\hline 33 & 57 & 1,63 & 21,45 & 23 & 178 & 66 & 102 & 50 \\
\hline 34 & 76 & 1,7 & 26,30 & 47 & 208 & - & - & 112 \\
\hline 35 & 62 & 1,61 & 23,92 & 49 & 217 & 39 & 153 & 127 \\
\hline 36 & 69 & 1,65 & 25,34 & 42 & 163 & 36 & 107 & 100 \\
\hline 37 & 94 & 1,76 & 30,35 & 41 & 178 & 33 & 101 & 219 \\
\hline 38 & 58 & 1,65 & 21,30 & 37 & 189 & 48 & 113 & 136 \\
\hline 39 & 70 & 1,68 & 24,80 & 57 & 217 & 57 & 145 & 73 \\
\hline 40 & 65 & 1,65 & 23,88 & 58 & 211 & 49 & 139 & 114 \\
\hline 41 & 66 & 1,58 & 26,44 & 45 & 163 & 51 & 85 & 135 \\
\hline 42 & 52 & 1,6 & 20,31 & 52 & 193 & 42 & 125 & 130 \\
\hline 43 & 85 & 1,54 & 35,84 & 52 & 221 & 70 & 131 & 100 \\
\hline 44 & 73 & 1,66 & 26,49 & 61 & 162 & - & - & 190 \\
\hline 45 & 97 & 1,72 & 32,79 & 41 & 201 & 48 & 136 & 86 \\
\hline 46 & 51 & 1,52 & 22,07 & 63 & 241 & 51 & 169 & 103 \\
\hline 47 & 85 & 1,81 & 25,91 & 29 & 156 & 29 & 98 & 144 \\
\hline 48 & 60 & 1,6 & 23,44 & 26 & 166 & 28 & 126 & 60 \\
\hline 49 & 55 & 1,6 & 21,48 & 64 & 183 & 46 & 97 & 200 \\
\hline 50 & 69 & 1,64 & 25,65 & 55 & 233 & 36 & 178 & 95 \\
\hline
\end{tabular}

Legenda: Lipides e apolipoproteinas em mg/dL; glicose em mg/dL; PCR-as em mg/L; PCR-asproteína $\mathrm{C}$ reativa de alta sensibilidade. 
Anexo 3. Tabela com os dados da cinética do grupo controle

\begin{tabular}{|c|c|c|c|c|c|c|c|c|c|}
\hline Paciente & k1 & k2 & k5 & $k 1,2$ & $k 3,5$ & $\mathrm{k} 4,5$ & FCR CE & FCRTG & TFL \\
\hline 1 & 0,0191 & 0,00531 & 2,63 & 0,34 & 0,144 & 0,0001 & 0,007182 & 0,026821 & 0,019811 \\
\hline 2 & 0,169 & 0,0111 & 0,17 & 0,0962 & 0,099 & 0,00471 & 0,0276 & 0,0467 & 0,0181 \\
\hline 3 & 0,308 & 0,00414 & 0,0709 & 0,0284 & 19,1 & 0,0001 & 0,0427 & 0,0702 & 2,476 \\
\hline 4 & $1.10^{-8}$ & 0,00981 & 0,112 & 0,231 & 0,01 & 0,0504 & 0,00941 & 0,03615 & 0,042 \\
\hline 5 & 0,041 & $1.10^{-9}$ & 0,163 & 0,06 & 0,155 & 0,0001 & $1,68.10^{-9}$ & 0,000421 & 0,000354 \\
\hline 6 & 0,0426 & 0,00469 & 10 & 0,0639 & 0,074 & 0,0001 & 0,00729 & 0,0126 & 0,00529 \\
\hline 7 & 0,045 & 0,0055 & 1,154 & 0,0494 & 0,142 & 0,0001 & 0,009546 & 0,023991 & 0,014685 \\
\hline 8 & 0,153 & 0,0118 & 0,107 & 0,101 & 0,0399 & 0,0001 & 0,012177 & 0,050282 & 0,025321 \\
\hline 9 & 0,0865 & 0,00245 & 0,258 & 0,0401 & 0,124 & 0,00326 & 0,00729 & 0,0292 & 0,0183 \\
\hline 10 & 0,0463 & $1.10^{-9}$ & 10 & 0,00929 & 0,138 & 0,0001 & $5,99 \cdot 10^{-9}$ & 0,00206 & 0,00157 \\
\hline 11 & 0,0149 & $1.10^{-9}$ & 0,15 & 0,0309 & 0,0461 & 0,00946 & $1,52.10^{-9}$ & 0,02253 & 0,02 \\
\hline 12 & 0,166 & 0,0264 & 0,0235 & 0,0996 & 0,01 & 0,0211 & 0,0557 & 0,051 & 0,0174 \\
\hline 13 & 0,0179 & $7,71.10^{-5}$ & 0,121 & 0,0499 & 0,173 & 0,0126 & 0,000104 & 0,0357 & 0,0453 \\
\hline 14 & 0,068 & 0,0157 & 0,0678 & 0,001 & 0,01 & 0,103 & 0,06573 & 0,06837 & 0,107767 \\
\hline 15 & 0,074 & 0,0173 & 0,0404 & 0,0668 & 0,01 & 0,0172 & 0,029194 & 0,0379 & $1,47.10^{-2}$ \\
\hline 16 & 0,0713 & 0,0287 & 0,0114 & 0,11 & 0,01 & & 0,03 & & \\
\hline 17 & 0,25 & 0,0056 & 10 & 0,0654 & 0,0444 & 0,00468 & 0,02512 & $0,04 \mathrm{c}$ & 0,01 \\
\hline 18 & 0,0567 & 0,00585 & 0,303 & & 0,182 & & 0,012 & 0,4 & \\
\hline 19 & 0,636 & 0,0121 & 0,192 & 0,0394 & 0,0551 & 0,0128 & 0,169 & 0,2457 & 0,02918 \\
\hline 20 & 0,064 & 0,00631 & 0,245 & 0,0 & 0,125 & & 0,00 & 0,022312 & 0,0 \\
\hline 21 & 0,375 & $1.10^{-9}$ & 0,433 & 0,12 & 0,232 & $3,48.10^{-5}$ & $4,12 \cdot 10^{-9}$ & 0,02 & 0,009915 \\
\hline 22 & 0,112 & 0,000295 & 0,41 & 0,0 & 0,0 & 0,00 & 0,0 & & 866 \\
\hline 23 & 0,0865 & 0,00245 & 0,258 & 0,0401 & 0,124 & 0,00326 & 0,00326 & 0,0236 & 0,0151 \\
\hline 24 & 0,102 & 0,00598 & 0,205 & 0,0255 & 0,04 & 0,00369 & 0,020355 & 0,3783 & 0,014013 \\
\hline 25 & 0,0391 & $1.10^{-9}$ & 10 & 0,0107 & 0,0105 & 0,0001 & $4,65 \cdot 10^{-9}$ & 0,000558 & 0,000197 \\
\hline 26 & 0,105 & $1.10^{-9}$ & 0,36 & 9,67 & 0,01 & 0,0249 & $2,10.10^{-9}$ & 0,027 & 0,0219 \\
\hline 27 & 0,161 & 9,01 & 0,029 & 0,0 & 0,0 & & & & 286 \\
\hline 28 & 0,121 & 0,00367 & 0,01 & 0,05 & 0,0708 & 0,0001 & 0,01167 & 0,01 & 0,0 \\
\hline 29 & 0,0013 & 0,000918 & 2,92 & 0,0992 & 0,0866 & 0,00134 & 0,026112 & 0,040791 & 0,018583 \\
\hline 30 & 0,137 & $1.10-9$ & 0,0155 & 0,142 & 0,01 & 1,87 & $1,97.10^{-9}$ & 0,0265 & 0,1308 \\
\hline 31 & $1,27 \cdot 10^{-3}$ & 0,000437 & 10 & 0,0251 & 0,0252 & 0,0001 & 0,000451 & 0,00108 & 0,000626 \\
\hline 32 & 0,257 & 0,00724 & 10 & 0,0318 & 0,0111 & 0,0001 & 0,0535 & 0,0562 & 0,00217 \\
\hline 33 & 0,072 & 0,002 & 10 & 1,96 & 0,0438 & 0,0001 & 0,008517 & 0,01315 & 0,004349 \\
\hline 34 & 0,203 & 0,00353 & 0,0694 & 0,0654 & 0,0554 & & 0,0136 & & 0,00297 \\
\hline 35 & 0,0568 & 0,00894 & 10 & 0,0452 & 0,0464 & & 0,0168 & & 0,00782 \\
\hline 36 & 0,0717 & 0,00883 & 0,216 & 0,0493 & 0,13 & 0,00236 & 0,0184 & 0,0415 & 0,0261 \\
\hline 37 & 0,0975 & $1.10^{-9}$ & 0,0101 & 0,0219 & 0,0374 & 0,0001 & $5,45.10^{-9}$ & 0,000695 & 0,00027 \\
\hline 38 & 0,0534 & $1.10^{-9}$ & 1,98 & 0,0422 & 0,0269 & 0,013 & $2,26.10^{-9}$ & 0,0287 & 0,01635 \\
\hline 39 & 0,124 & 0,00834 & 10 & 0,0491 & 0,0628 & 0,0001 & 0,0252 & 0,0346 & 0,00929 \\
\hline 40 & 0,072 & 0,0196 & 3,53 & 0,115 & 0,0596 & 0,00217 & 0,0273 & 0,0392 & 0,0113 \\
\hline 41 & 0,0662 & $1,42.10^{-2}$ & 0,287 & 0,029 & 0,05 & 0,0001 & 0,0313 & 0,0455 & 0,0167 \\
\hline 42 & 0,176 & 0,0195 & 0,0281 & 0,0755 & 0,01 & 0,0001 & 0,051841 & 0,050282 & 0,002147 \\
\hline 43 & 0,0661 & 0,00952 & 4,79 & 0,457 & 0,0568 & 0,0001 & 0,019273 & 0,029254 & 0,009958 \\
\hline 44 & 0,109 & $1.10^{-9}$ & 2,15 & 0,0784 & 0,141 & 0,013 & $2,88.10^{-9}$ & 0,05566 & 0,0366 \\
\hline 45 & 0,0228 & 0,00606 & 0,585 & 0,0515 & 0,15 & 0,00234 & 0,00784 & 0,030417 & 0,023195 \\
\hline 46 & 0,157 & $1.10^{-9}$ & 0,01 & 0,0216 & 0,0154 & 0,872 & $8,29 \cdot 10^{-9}$ & 0,0411 & 0,0361 \\
\hline 47 & $1.10-8$ & 0,0154 & 0,01 & 1,2 & 0,128 & 0,0379 & 0,015228 & 0,010919 & 0,041835 \\
\hline 48 & 0,165 & 1,13 & 10 & 0,106 & 0,103 & 0,00493 & 0,03 & 0,0495 & 0,012 \\
\hline 49 & 0,108 & 0,00834 & 0,644 & 0,0657 & 0,0635 & 0,00913 & 0,019647 & 0,048433 & 0,020556 \\
\hline 50 & 0,00164 & 0,00895 & 0,156 & 0,216 & 0,292 & 0,0001 & 0,00866 & 0,01908 & 0,011869 \\
\hline
\end{tabular}

Legenda: TFR-taxa fracional de remoção; TFL- taxa fracional de lipólise; $k_{x, y}$ (constante de transferência do compartimento $x$ para y) expressas em $\min ^{-1}$. 
Anexo 4. Tabelas dos dados da cinética dos pacientes HF com CAC

\begin{tabular}{|c|c|c|c|c|c|c|c|c|c|}
\hline Paciente & FCRCE & FCRTG & TFL & k1 & $k 2$ & k5 & $k 1,2$ & $k 3,5$ & $k 4,5$ \\
\hline 1 & 0,004329 & 0,05997 & 0,06538 & 0,015 & 0,003326 & 0,359 & 0,0383 & 0,356 & 0,00468 \\
\hline 2 & 0,00984 & 0,229 & 0,014 & $1.10^{-8}$ & 0,0113 & 0,367 & 0,075 & 0,105 & 0,0001 \\
\hline 3 & 0,0388 & 0,0274 & 0,0233 & 0,061 & 0,00281 & 0,224 & 0,17 & 0,21 & 8,79 \\
\hline 4 & 0,0326 & 0,0387 & 0,00875 & 0,5 & 0,00748 & 0,11 & 0,14 & 0,17 & 0,0001 \\
\hline 5 & 0,00313 & 0,0278 & 0,0219 & 0,0443 & 0,00203 & 0,86 & 0,076 & 0,14 & 0,00732 \\
\hline 6 & 0,000017 & 0,0224 & 0,0211 & 0,00411 & 0,000015 & 10 & 0,0305 & 0,0357 & 0,0143 \\
\hline 7 & 0,000146 & 0,0294 & 0,1 & 0,076 & $8,41 \cdot 10^{-5}$ & 0,01 & 0,87 & 0,01 & 0,87 \\
\hline 8 & 0,0036 & 0,0241 & 2,668 & 0,0741 & 0,00265 & 0,00237 & 0,198 & 0,003074 & 0,872 \\
\hline 9 & $2,58.10^{-9}$ & 0,00947 & 0,00555 & 0,103 & $1.10^{-9}$ & 0,17 & 0,0657 & 0,0702 & 0,00279 \\
\hline 10 & 0,00972 & 0,0174 & 0,0077 & 0,00137 & 0,037 & 10 & 0,0112 & 0,01 & 0,0001 \\
\hline 11 & 0,00104 & 0,011 & 0,009122 & 0,0896 & 0,000796 & 0,147 & 0,28 & 0,18 & 0,00533 \\
\hline 12 & $2,49.10^{-9}$ & 0,0114 & 0,0063 & 0,0363 & $1.10^{-9}$ & 5,3 & 0,0242 & 0,0198 & 0,00404 \\
\hline 13 & 0,001328 & 0,03171 & 0,01875 & 0,0732 & $1.10^{-9}$ & 0,1689 & 0,02197 & 0,0299 & 0,000186 \\
\hline 14 & $2,26.10^{-9}$ & 0,0331 & 0,078 & 0,07219 & $1.10^{-9}$ & 0,0258 & 0,0572 & 0,0445 & 0,187 \\
\hline 15 & $2,66.10^{-9}$ & 0,014 & 0,00861 & 0,0962 & $1.10^{-9}$ & 1,02 & 0,0578 & 0,0927 & 0,00351 \\
\hline 16 & 0,00132 & 0,0317 & 0,0187 & 0,0844 & 0,000675 & 8,47 & 0,00859 & 0,045 & 0,00142 \\
\hline 17 & $1,8.10^{-9}$ & 0,0329 & 0,19 & 0,186 & $1.10^{-9}$ & 0,0206 & 0,232 & 0,01 & 0,87 \\
\hline 18 & 0,015 & 0,0158 & 0,000467 & 0,11 & 0,00814 & 10 & 0,114 & 0,01 & 0,0001 \\
\hline 19 & $1,61 \cdot 10^{-9}$ & 0,0393 & 0,15 & 0,1 & $1.10-9$ & 0,0299 & 0,17 & 0,01 & 0,872 \\
\hline 20 & 0,003411 & 0,043 & 0,024 & 0,287 & 0,00134 & 0,345 & 0,195 & 0,161 & 0,0136 \\
\hline
\end{tabular}

Legenda TFR-taxa fracional de remoção; TFL- taxa fracional de lipólise; $k_{x, y}$ (constante de transferência do compartimento $x$ para y) expressas em $\mathrm{min}^{-1}$. 
Anexo 5. Tabelas dos dados da cinética dos pacientes HF sem CAC

\begin{tabular}{|c|c|c|c|c|c|c|c|c|c|}
\hline Paciente & FCRCE & FCRTG & TFL & k1 & k2 & k5 & $\mathrm{k} 1,2$ & $k 3,5$ & $\mathrm{k} 4,5$ \\
\hline 1 & 0,00498 & 0,059 & 0,0455 & 0,11 & 0,00265 & 0,76 & 0,12 & 0,241 & 0,0157 \\
\hline 2 & $6,92 \cdot 10^{-6}$ & 0,0262 & 0,0206 & 0,13 & $3,79.10^{-6}$ & 0,297 & 0,158 & 0,203 & 0,00957 \\
\hline 3 & 0,08216 & 0,0628 & 0,045 & 0,08262 & 0,00495 & 3,649 & 0,113 & 0,176 & 1,837 \\
\hline 4 & $1,89.10^{-9}$ & 0,0174 & 0,0105 & 0,127 & $1.10^{-9}$ & 1,69 & 0,142 & 0,0518 & 0,008211 \\
\hline 5 & $2,87 \cdot 10^{-9}$ & 0,000451 & 0,000277 & 0,0625 & $1.10^{-9}$ & 0,01 & 0,0334 & 0,0596 & 0,0001 \\
\hline 6 & $1,47.10^{-9}$ & 0,00964 & 0,00858 & 0,0303 & $1.10^{-9}$ & 0,111 & 0,0639 & 0,0798 & 0,00405 \\
\hline 7 & $1,48.10^{-9}$ & 0,0148 & 0,01148 & 0,0316 & $1.10^{-9}$ & 10 & 0,0649 & 0,0411 & 0,00788 \\
\hline 8 & 0,0144 & 0,0483 & 0,021 & 0,39 & 0,0044 & 0,299 & 0,164 & 0,227 & 0,00727 \\
\hline 9 & 0,00145 & 0,0209 & 0,0153 & 0,0463 & 0,000723 & 10 & 0,0442 & 0,052 & 0,0069 \\
\hline 10 & $1,68 \cdot 10^{-9}$ & 0,000399 & 0,000332 & 0,0524 & $1.10^{-9}$ & 0,0927 & 0,0762 & 0,177 & 0,0001 \\
\hline 11 & $2,22 \cdot 10^{-9}$ & 0,075 & 0,06 & 0,0336 & $1.10^{-9}$ & 0,26 & 0,0275 & 0,0354 & 4,57 \\
\hline 12 & 0,00506 & 0,0111 & 0,00578 & 0,051 & 0,00267 & 0,0172 & 0,051 & 0,01 & 0,00515 \\
\hline 13 & $2,12 \cdot 10^{-9}$ & 0,0249 & 0,0385 & 0,0793 & $1.10^{-9}$ & 0,0186 & 0,0706 & 0,01 & 0,0647 \\
\hline 14 & 0,0117 & 0,0418 & 0,0328 & 0,164 & 0,00844 & 0,171 & 0,393 & 0,348 & 1,443 \\
\hline 15 & 0,0108 & 0,0566 & 0,1562 & 0,15 & 0,00611 & 0,0397 & 0,179 & 0,01 & 0,87 \\
\hline 16 & 0,00939 & 0,0254 & 0,0125 & 0,547 & 0,0432 & 0,127 & 0,459 & 0,361 & 0,00526 \\
\hline
\end{tabular}

Legenda anexo 5: TFR-taxa fracional de remoção; TFL- taxa fracional de lipólise; $\mathrm{k}_{x, y}$ (constante de transferência do compartimento $\mathrm{x}$ para y) expressas em $\mathrm{min}^{-1}$. 
Anexo 6. Tabelas dos dados laboratoriais dos pacientes HF com CAC

\begin{tabular}{|c|c|c|c|c|c|c|c|c|c|c|c|c|}
\hline Paciente & Sexo & $\begin{array}{l}\text { Idade } \\
\text { anos }\end{array}$ & $\begin{array}{c}\mathrm{CT} \\
\mathrm{mg} / \mathrm{dL}\end{array}$ & $\begin{array}{l}\mathrm{HDL} \\
\mathrm{mg} / \mathrm{dL}\end{array}$ & $\begin{array}{l}\mathrm{LDL} \\
\mathrm{mg} / \mathrm{dL}\end{array}$ & $\begin{array}{c}\mathrm{TG} \\
\mathrm{mg} / \mathrm{dL}\end{array}$ & $\begin{array}{l}\text { GLIC } \\
\mathrm{mg} / \mathrm{dL}\end{array}$ & $\begin{array}{l}\mathrm{lp}(\mathrm{a}) \\
\mathrm{mg} / \mathrm{dl}\end{array}$ & $\begin{array}{c}\text { apoA1 } \\
\mathrm{g} / \mathrm{l}\end{array}$ & $\begin{array}{c}\text { apoB } \\
\text { g/l }\end{array}$ & $\begin{array}{l}\mathrm{PCR} \\
\mathrm{mg} / \mathrm{l}\end{array}$ & $\begin{array}{l}\mathrm{IMC} \\
\mathrm{Kg} / \mathrm{m}^{2}\end{array}$ \\
\hline 1 & 1 & 43 & 421 & 54 & 330 & 183 & 94 & 171 & 161,3 & 197,2 & 3,06 & 28,04 \\
\hline 2 & 1 & 39 & 357 & 27 & 288 & 212 & 101 & 282 & 99,9 & 219,5 & 4,14 & 26,37 \\
\hline 3 & 1 & 48 & 225 & 48 & 157 & 101 & 95 & 79 & 129,6 & 107,8 & 5,33 & 33,44 \\
\hline 4 & 1 & 40 & 267 & 46 & 203 & 89 & 97 & 27 & 134,9 & 149,6 & 1,66 & 20,15 \\
\hline 5 & 1 & 27 & 302 & 27 & 228 & 316 & 98 & 153 & 90,6 & 168,9 & 1,5 & 25,79 \\
\hline 6 & 1 & 51 & 431 & 40 & 355 & 178 & 84 & 31,4 & 136,5 & 229,2 & 1 & 21,45 \\
\hline 7 & 2 & 49 & 470 & 37 & 385 & 242 & 106 & 74,8 & 119,1 & 238,9 & 1,7 & 28,39 \\
\hline 8 & 2 & 66 & 589 & 46 & 488 & 276 & 107 & 113 & 138,9 & 325,3 & 3,04 & 30,24 \\
\hline 9 & 1 & 47 & 423 & 53 & 345 & 126 & 89 & 100 & 138,3 & 193,7 & 1,22 & 24,46 \\
\hline 10 & 2 & 58 & 409 & 49 & 335 & 125 & 91 & 23 & 135,2 & 216,4 & 4,66 & 23,46 \\
\hline 11 & 2 & 54 & 391 & 62 & 296 & 164 & 93 & 30,9 & 165,2 & 126,4 & 3,2 & 26,71 \\
\hline 12 & 2 & 53 & 549 & 66 & 444 & 196 & 95 & 8,45 & 157 & 241 & 1,69 & 23,41 \\
\hline 13 & 2 & 53 & 450 & 83 & 347 & 99 & 86 & 80 & 203 & 174,5 & & 22,80 \\
\hline 14 & 2 & 55 & 401 & 44 & 333 & 119 & 103 & 23 & 129,9 & 214,6 & 0,18 & 33,33 \\
\hline 15 & 2 & 46 & 391 & 43 & 323 & 125 & 92 & 181 & 130 & 208,2 & 6,39 & 22,43 \\
\hline 16 & 2 & 68 & 322 & 64 & 221 & 183 & 88 & 30 & 180,3 & 166,2 & 5,36 & 22,10 \\
\hline 17 & 1 & 50 & 390 & 43 & 303 & 220 & 89 & 33 & 135,5 & 209 & 4,96 & 38,09 \\
\hline 18 & 1 & 24 & 491 & 48 & 418 & 124 & 88 & 102 & 120,8 & 214,7 & 7,48 & 24,74 \\
\hline 19 & 2 & 60 & 430 & 60 & 332 & 191 & 91 & 42 & 169,4 & 185,8 & 0,48 & 29,24 \\
\hline 20 & 2 & 56 & 308 & 52 & 227 & 144 & 109 & 134 & 155,2 & 157,3 & 2,3 & 30,30 \\
\hline
\end{tabular}


Anexo 7. Tabelas dos dados laboratoriais dos pacientes HF sem CAC

\begin{tabular}{|c|c|c|c|c|c|c|c|c|c|c|c|c|}
\hline Paciente & Sexo & $\begin{array}{l}\text { Idade } \\
\text { anos }\end{array}$ & $\begin{array}{c}\mathrm{CT} \\
\mathrm{mg} / \mathrm{dL}\end{array}$ & $\begin{array}{l}\mathrm{HDL} \\
\mathrm{mg} / \mathrm{dL}\end{array}$ & $\begin{array}{l}\mathrm{LDL} \\
\mathrm{mg} / \mathrm{dL}\end{array}$ & $\begin{array}{c}\mathrm{TG} \\
\mathrm{mg} / \mathrm{dL}\end{array}$ & $\begin{array}{l}\text { GLIC } \\
\mathrm{mg} / \mathrm{dL}\end{array}$ & $\begin{array}{l}\mathrm{lp}(\mathrm{a}) \\
\mathrm{mg} / \mathrm{dl}\end{array}$ & $\begin{array}{c}\text { apoA1 } \\
\text { g/l }\end{array}$ & $\begin{array}{c}\text { apoB } \\
\text { g/l }\end{array}$ & $\begin{array}{l}\text { PCR } \\
\mathrm{mg} / \mathrm{dl}\end{array}$ & $\underset{\mathrm{Kg} / \mathrm{m}^{2}}{\mathrm{IMC}}$ \\
\hline 1 & $F$ & 32 & 364 & 70 & 252 & 211 & 73 & 80 & 218,7 & 179,8 & 7,12 & 24,39 \\
\hline 2 & $\mathrm{~F}$ & 58 & 400 & 59 & 298 & 215 & 94 & 34 & 156,8 & 223,3 & 1,66 & 22,68 \\
\hline 3 & M & 51 & 310 & 49 & 235 & 131 & 85 & 37 & 135,7 & 151,2 & 2,62 & 20,08 \\
\hline 4 & $F$ & 70 & 260 & 56 & 170 & 169 & 89 & 273 & 157,1 & 125,7 & 0,87 & 27,11 \\
\hline 5 & $\mathrm{~F}$ & 54 & 323 & 46 & 225 & 341 & 97 & 54 & 150,3 & 129,5 & 2,58 & 25,54 \\
\hline 6 & $\mathrm{~F}$ & 54 & 423 & 39 & 352 & 159 & 98 & 94 & 1,22 & 2,28 & 3,3 & 23,71 \\
\hline 7 & M & 31 & 342 & 32 & 288 & 110 & 95 & 46 & 94,6 & 179,6 & 0,75 & 27,59 \\
\hline 8 & M & 39 & 330 & 35 & 262 & 163 & 102 & 42 & 113,5 & 170,2 & 1,31 & 31,95 \\
\hline 9 & $F$ & 43 & 390 & 33 & 340 & 87 & 87 & 12,89 & 114,4 & 195,1 & 12,89 & 26,04 \\
\hline 10 & $M$ & 30 & 349 & 53 & 265 & 154 & 79 & 41,27 & 135,7 & 175 & 0,83 & 21,16 \\
\hline 11 & $F$ & 60 & 357 & 57 & 246 & 268 & 96 & 121 & 163,8 & 189,6 & 5,11 & 29,69 \\
\hline 12 & $M$ & 50 & 307 & 65 & 229 & 66 & 112 & 231 & 154,4 & 138,4 & 2,19 & 23,98 \\
\hline 13 & $\mathrm{~F}$ & 43 & 302 & 36 & 224 & 212 & 89 & 10 & 119,1 & 155,2 & 2,9 & 31,01 \\
\hline 14 & $F$ & 52 & 281 & 39 & 206 & 182 & 102 & 114,2 & 145 & 170 & 6,93 & 25,40 \\
\hline 15 & $M$ & 29 & 424 & 62 & 392 & 133 & 97 & 77,9 & 131,4 & 197 & 4,2 & 26,54 \\
\hline 16 & $M$ & 33 & 278 & 33 & 186 & 293 & 85 & 20 & 125,1 & 152,2 & 2,28 & 28,22 \\
\hline
\end{tabular}

Legenda: Lipides e apolipoproteinas em mg/dL; glicose em mg/dL; PCR-as em mg/L; PCR-as- proteína C reativa de alta sensibilidade 
Anexo 8. Termo de consentimento livre e esclarecido

\section{HOSPITAL DAS CLÍNICAS DA FACULDADE DE MEDICINA DA UNIVERSIDADE DE SÃO PAULO-HCFMUSP \\ TERMO DE CONSENTIMENTO LIVRE E ESCLARECIDO}

DADOS DE IDENTIFICAÇÃO DO SUJEITO DA PESQUISA OU RESPONSÁVEL LEGAL

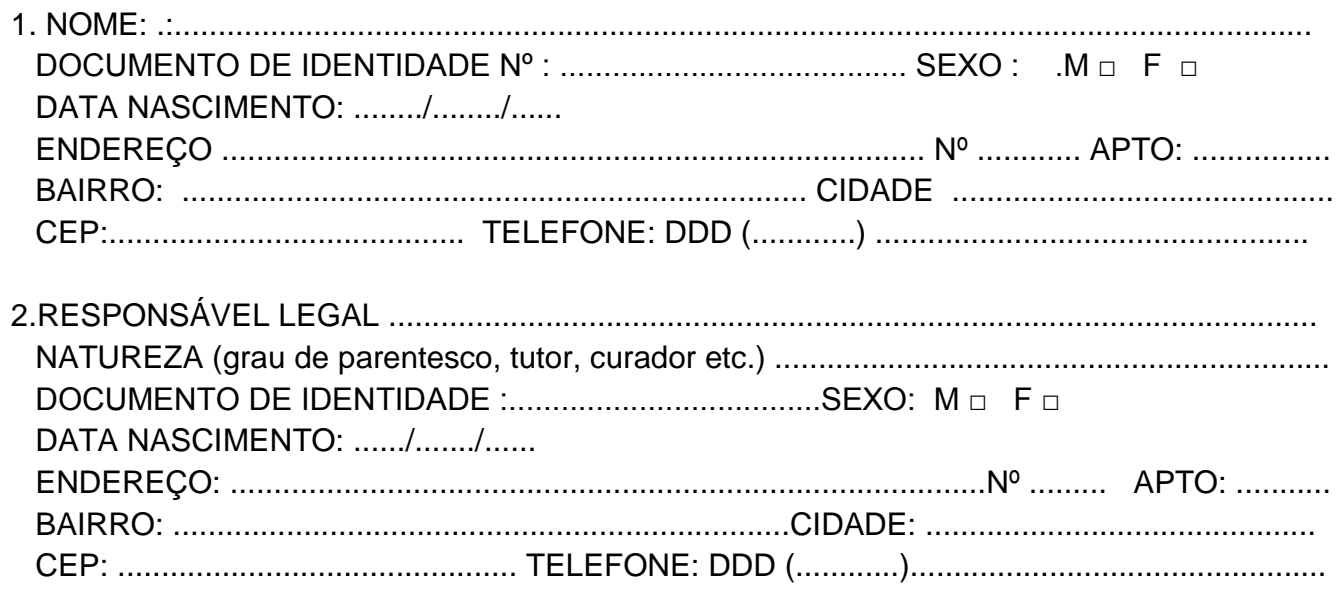

DADOS SOBRE A PESQUISA

1. TÍTULO DO PROTOCOLO DE PESQUISA :METABOLISMO DE QUILOMÍCRONS E ATEROSCLEROSE SUBCLÍNICA EM PORTADORES DE HIPERCOLESTEROLEMIA FAMILIAR HETEROZIGÓTICA

2. PESQUISADOR EXECUTANTE : Marcia Maria Carneiro

CARGO/FUNÇÃO: Médico. INSCRIÇÃO CONSELHO REGIONAL No 6019

UNIDADE DO HCFMUSP: Instituto do Coração - Unidade Clínica de Lípides

PESQUISADOR RESPONSÁVEL: RAUL DIAS DOS SANTOS FILHO

CARGO/FUNÇÃO : MÉDICO INSCRIÇÃO CONSELHO REGIONAL N57825

UNIDADE DO HCFMUSP: Instituto do Coração -Unidade Clínica de Lípides

3. AVALIAÇÃO DO RISCO DA PESQUISA:

$\begin{array}{ll}\text { RISCO MÍNIMO } & \text { RISCO MÉDIO } \\ \text { RISCO BAIXO } & \text { RISCO MAIOR }\end{array}$

IV.DURAÇÃO DA PESQUISA : .. 48 meses 


\section{VERSÃO 2}

\section{HOSPITAL DAS CLÍNICAS DA FACULDADE DE MEDICINA DA UNIVERSIDADE DE SÃO PAULO- HCFMUSP}

1.O Sr(a) é portador(a) de uma doença de origem genética que é a Hipercolesterolemia familiar (HF) ,doença que provoca elevados níveis de colesterol no sangue (gordura no sangue) e maior risco de problemas no coração. Além dos altos níveis de colesterol no sangue é sabido que o metabolismo mais lento do colesterol após a alimentação é um fator que coopera para o desenvolvimento de aterosclerose (placa de gordura que obstrui as artérias). Atualmente também já se sabe que a presença de cálcio nas coronárias (artérias do coração) avaliada por tomografia implica em maior risco de se desenvolver doença aterosclerótica (obstrução das artérias por placas de gordura). Contudo não sabemos ainda se o estudo do metabolismo das gorduras após a alimentação está alterado em pacientes com a HF e se essa poderia se correlacionar com calcificação das coronárias. Este trabalho tem como objetivo avaliar esta questão

2. Desta forma estamos convidando o $\operatorname{Sr}(a)$, que anteriormente realizou o estudo de tomografia das coronárias, para avaliar se existe algum distúrbio no metabolismo dessas gorduras. Para o estudo do metabolismo será necessário puncionar uma veia do braço para que se possa injetar uma quantidade mínima de gordura $(0,1 \mathrm{ml})$ que será marcada com uma substância que tem uma quantidade mínima de radioatividade cerca de 20 vezes menos a de uma radiografia comum, ou seja, pode ser injetada sem problemas para o organismo. Após a injeção dessa substância uma veia de outro braço deverá ser puncionada para coleta de amostras de sangue em tempos pré-estabelecidos: 2, 4, 6, $10,15,20,30$, 45 e 60 minutos para que dessa forma o metabolismo possa ser estudado. Se porventura o $\mathrm{Sr}(\mathrm{a})$ estiver em uso prévio de medicações que reduzem o colesterol,este deverá ser suspenso por um período de seis semanas.É importante frisar que a suspensão temporária dessas medicações não acarreta maior risco. Após esse período sem medicação será realizado o estudo do metabolismo conforme descrito acima.

3. As complicações da punção da veia também são mínimas a saber: pequeno hematoma no local da punção , dor no momento da punção sem maiores complicações. É importante lembrar que alguns pacientes podem apresentar tonturas e suor frio devido ao jejum de 12 horas ou ao fato de se impressionarem com a coleta de sangue. A quantidade de radioatividade utilizada nesse estudo é muito inferior à de uma radiografia comum.

4. Assim com essa avaliação poderemos responder como se comporta o metabolismo das gorduras em pacientes com HF e mais, se a presença de calcificação das coronárias implica em metabolismo mais lento. A participação é totalmente voluntária e você pode se recusar a participar do estudo a qualquer momento, ou sair do mesmo, sem perder quaisquer benefícios ou tratamento nesta instituição.

5. Caso sejam detectadas alterações precoces seu médico discutirá com você a instituição de terapias preventivas pertinentes, o que poderá ser benéfico no seu caso. O $\operatorname{Sr}(a)$ não vai ter nenhum custo para a realização dos exames realizados nesta pesquisa

6 - Garantia de acesso: em qualquer etapa do estudo, você terá acesso aos profissionais responsáveis pela pesquisa para esclarecimento de eventuais dúvidas. O principal investigador é o Dr Raul Dias dos Santos Filho. que pode ser encontrado no endereço Unidade Clínica de Lípides -InCor HCFMUSP.Endereço: Av. Dr. Eneas C. Aguiar no 44 cep 05403-000 Pinheiros São Paulo. Telefone(s) (011) 30695320. 
HOSPITAL DAS CLÍNICAS DA FACULDADE DE MEDICINA DA UNIVERSIDADE DE SÃO PAULOHCFMUSP

Se você tiver alguma consideração ou dúvida sobre a ética da pesquisa, entre em contato com o Comitê de Ética em Pesquisa (CEP) - Rua Ovídio Pires de Campos, 225 - 5 andar - tel: 3069-6442 ramais 16, 17, 18 ou 20, FAX: 3069-6442 ramal 26 - E-mail: cappesq@hcnet.usp.br

7 - É garantida a liberdade da retirada de consentimento a qualquer momento e deixar de participar do estudo, sem qualquer prejuízo à continuidade de seu tratamento na Instituição;

8 - Direito de confidencialidade - As informações obtidas serão analisadas em conjunto com outros pacientes, não sendo divulgado a identificação de nenhum paciente;

9 - Direito de ser mantido atualizado sobre os resultados parciais das pesquisas, quando em estudos abertos, ou de resultados que sejam do conhecimento dos pesquisadores;

10 - Não há despesas pessoais para o participante em qualquer fase do estudo, incluindo exames e consultas. Também não há compensação financeira relacionada à sua participação. Se existir qualquer despesa adicional, ela será absorvida pelo orçamento da pesquisa.

11 - Compromisso do pesquisador de utilizar os dados e o material coletado somente para esta pesquisa. 
HOSPITAL DAS CLÍNICAS DA FACULDADE DE MEDICINA DA UNIVERSIDADE DE SÃO PAULOHCFMUSP

Acredito ter sido suficientemente informado a respeito das informações que li ou que foram lidas para mim, descrevendo o estudo. " METABOLISMO DE QUILOMÍCRONS E ATEROSCLEROSE SUBCLÍNICA EM PORTADORES DE HIPERCOLESTEROLEMIA FAMILIAR HETEROZIGÓTICA".

Eu discuti com o Dr. Raul Dias dos Santos Filho sobre a minha decisão em participar nesse estudo. Ficaram claros para mim quais são os propósitos do estudo, os procedimentos a serem realizados, seus desconfortos e riscos, as garantias de confidencialidade e de esclarecimentos permanentes. Ficou claro também que minha participação é isenta de despesas e que tenho garantia do acesso a tratamento hospitalar quando necessário. Concordo voluntariamente em participar deste estudo e poderei retirar o meu consentimento a qualquer momento, antes ou durante o mesmo, sem penalidades ou prejuízo ou perda de qualquer benefício que eu possa ter adquirido, ou no meu atendimento neste Serviço.

11

Assinatura da testemunha

Data $1 \quad 1$

para casos de pacientes menores de 18 anos, analfabetos, semi-analfabetos ou portadores de deficiência auditiva ou visual.

(Somente para o responsável do projeto)

Declaro que obtive de forma apropriada e voluntária o Consentimento Livre e Esclarecido deste paciente ou representante legal para a participação neste estudo. 


\section{REFERÊNCIAS}


1. Goldstein JL, Hobbs HH, Brown MS. The metabolic basis of inherited disease. 2001 ed., ed. B.A. Scriver CR, Sly WS, Valle D. Vol. 120. 2001, mc graw-hill: New york. 2863-913.

2. Brown MS, Goldstein JL. A receptor-mediated pathway for cholesterol homeostasis. Science, 1986. 232(4746): p. 34-47.

3. Marks D, et al. A review on the diagnosis, natural history, and treatment of familial hypercholesterolaemia. Atherosclerosis, 2003. 168(1): p. 1-14.

4. Hopkins PN, et al. Familial hypercholesterolemias: prevalence, genetics, diagnosis and screening recommendations from the National Lipid Association Expert Panel on Familial Hypercholesterolemia. J Clin Lipidol, 2011. 5(3 Suppl): p. S9-17.

5. Goldberg AC, et al. Familial hypercholesterolemia: screening, diagnosis and management of pediatric and adult patients: clinical guidance from the National Lipid Association Expert Panel on Familial Hypercholesterolemia. J Clin Lipidol, 2011. 5(3 Suppl): p. S1-8.

6. Villeger $\mathrm{L}$, et al. The UMD-LDLR database: additions to the software and 490 new entries to the database. Hum Mutat, 2002. 20(2): p. 81-7.

7. Civeira F. Guidelines for the diagnosis and management of heterozygous familial hypercholesterolemia. Atherosclerosis, 2004. 173(1): p. 55-68.

8. Cohen JC, et al. Sequence variations in PCSK9, low LDL, and protection against coronary heart disease. N Engl J Med, 2006. 354(12): p. 1264-72. 
9. Horton JD, Cohen JC, Hobbs HH. PCSK9: a convertase that coordinates LDL catabolism. J Lipid Res, 2009. 50 Suppl: p. S172-7.

10. Williams RR, et al. Diagnosing heterozygous familial hypercholesterolemia using new practical criteria validated by molecular genetics. Am J Cardiol, 1993. 72(2): p. 171-6.

11. Slack J. Risks of ischaemic heart-disease in familial hyperlipoproteinaemic states. Lancet, 1969. 2(7635): p. 1380-2.

12. Stone $\mathrm{NJ}$, et al. Coronary artery disease in $\mathbf{1 1 6}$ kindred with familial type II hyperlipoproteinemia. Circulation, 1974. 49(3): p. 476-88.

13. Mortality in treated heterozygous familial hypercholesterolaemia: implications for clinical management. Scientific Steering Committee on behalf of the Simon Broome Register Group. Atherosclerosis, 1999. 142(1): p. 105-12.

14. Mesquita $\mathrm{CH}$. Cinética do quilomicron marcado com 3H-TG e 14C-CE. Análise compartimental auxiliar. 1994, São Paulo: Instituto de Pesquisas Energéticas e Nucleares-IPEN.

15. Kotze MJ, et al. Phenotypic variation among familial hypercholesterolemics heterozygous for either one of two Afrikaner founder LDL receptor mutations. Arterioscler Thromb, 1993. 13(10): p. 1460-8.

16. Hirobe $\mathrm{K}$, et al. Coronary artery disease in heterozygous familial hypercholesterolemia. Atherosclerosis, 1982. 44(2): p. 201-10.

17. Hill JS, et al. Genetic and environmental factors affecting the incidence of coronary artery disease in heterozygous familial hypercholesterolemia. Arterioscler Thromb, 1991. 11(2): p. 290-7. 
18. Alonso R, et al. Heterozygous familial hypercholesterolemia in Spain. Description of 819 non related cases. Med Clin (Barc), 2002. 118(13): p. 487-92.

19. Mabuchi $\mathrm{H}$, et al. Development of coronary heart disease in familial hypercholesterolemia. Circulation, 1989. 79(2): p. 225-32.

20. Ferrieres J, et al. Coronary artery disease in heterozygous familial hypercholesterolemia patients with the same LDL receptor gene mutation. Circulation, 1995. 92(3): p. 290-5.

21. Hopkins $P N$, et al. Evaluation of coronary risk factors in patients with heterozygous familial hypercholesterolemia. Am J Cardiol, 2001. 87(5): p. 547-53.

22. Seed $M$, et al. Relation of serum lipoprotein(a) concentration and apolipoprotein(a) phenotype to coronary heart disease in patients with familial hypercholesterolemia. N Engl J Med, 1990. 322(21): p. 1494-9.

23. Tonstad S, et al. Risk factors related to carotid intima-media thickness and plaque in children with familial hypercholesterolemia and control subjects. Arterioscler Thromb Vasc Biol, 1996. 16(8): p. 984-91.

24. Wittekoek ME, et al. Differences in intima-media thickness in the carotid and femoral arteries in familial hypercholesterolemic heterozygotes with and without clinical manifestations of cardiovascular disease. Atherosclerosis, 1999. 146(2): p. 271-9.

25. Bertolini S, et al. Clinical expression of familial hypercholesterolemia in clusters of mutations of the LDL receptor gene that cause a receptordefective or receptor-negative phenotype. Arterioscler Thromb Vasc Biol, 2000. 20(9): p. E41-52. 
26. Smilde TJ, et al. Genetic and metabolic factors predicting risk of cardiovascular disease in familial hypercholesterolemia. Neth $\mathrm{J}$ Med, 2001. 59(4): p. 184-95.

27. Taira K, et al. Positive family history for coronary heart disease and 'midband lipoproteins' are potential risk factors of carotid atherosclerosis in familial hypercholesterolemia. Atherosclerosis, 2002. 160(2): p. 391-7.

28. Real JT, et al. Importance of HDL cholesterol levels and the total/ HDL cholesterol ratio as a risk factor for coronary heart disease in molecularly defined heterozygous familial hypercholesterolaemia. Eur Heart J, 2001. 22(6): p. 465-71.

29. Holmes DT, et al. Lipoprotein(a) is an independent risk factor for cardiovascular disease in heterozygous familial hypercholesterolemia. Clin Chem, 2005. 51(11): p. 2067-73.

30. Jansen $A C$, et al. The contribution of classical risk factors to cardiovascular disease in familial hypercholesterolaemia: data in 2400 patients. J Intern Med, 2004. 256(6): p. 482-90.

31. Redgrave TG, Maranhao RC. Metabolism of protein-free lipid emulsion models of chylomicrons in rats. Biochim Biophys Acta, 1985. 835(1): p. 104-12.

32. Cooper AD. Hepatic uptake of chylomicron remnants. J Lipid Res, 1997. 38(11): p. 2173-92.

33. Kindel $\mathrm{T}$, Lee DM, Tso $\mathrm{P}$. The mechanism of the formation and secretion of chylomicrons. Atheroscler Suppl, 2010. 11(1): p. 11-6.

34. Nakamura T, Kugiyama K. Triglycerides and remnant particles as risk factors for coronary artery disease. Curr Atheroscler Rep, 2006. 8(2): p. 107-10. 
35. Mamo JC, Wheeler JR. Chylomicrons or their remnants penetrate rabbit thoracic aorta as efficiently as do smaller macromolecules, including low-density lipoprotein, high-density lipoprotein, and albumin. Coron Artery Dis, 1994. 5(8): p. 695-705.

36. Proctor SD, Mamo JC. Retention of fluorescent-labelled chylomicron remnants within the intima of the arterial wall--evidence that plaque cholesterol may be derived from post-prandial lipoproteins. Eur J Clin Invest, 1998. 28(6): p. 497-503.

37. Maranhão RC, et al. Plasma kinetics of a chylomicron-like emulsion in patients with coronary artery disease. Atherosclerosis, 1996. 126(1): p. 15-25.

38. Santos RD, et al. Effect of pravastatin on plasma removal of a chylomicron-like emulsion in men with coronary artery disease. Am J Cardiol, 2000. 85(10): p. 1163-6.

39. Chacra AP, et al. Clearance of a $3 \mathrm{H}$-labeled chylomicron-like emulsion following the acute phase of myocardial infarction. Int J Cardiol, 2004. 93(2-3): p. 181-7.

40. Sposito AC, et al. Delayed intravascular catabolism of chylomicron-like emulsions is an independent predictor of coronary artery disease. Atherosclerosis, 2004. 176(2): p. 397-403.

41. Sposito AC, et al. Impaired intravascular triglyceride lipolysis constitutes a marker of clinical outcome in patients with stable angina undergoing secondary prevention treatment: a long-term follow-up study. J Am Coll Cardiol, 2004. 43(12): p. 2225-32.

42. Redgrave TG, et al. Uptake of artificial model remnant lipoprotein emulsions by the perfused rat liver. Lipids, 1988. 23(2): p. 101-5. 
43. Sposito AC, et al. LDL concentration is correlated with the removal from the plasma of a chylomicron-like emulsion in subjects with coronary artery disease. Atherosclerosis, 2002. 161(2): p. 447-53.

44. Sposito AC, et al. Atorvastatin enhances the plasma clearance of chylomicron-like emulsions in subjects with atherogenic dyslipidemia: relevance to the in vivo metabolism of triglyceride-rich lipoproteins. Atherosclerosis, 2003. 166(2): p. 311-21.

45. Rubinsztein DC, et al. Chylomicron remnant clearance from the plasma is normal in familial hypercholesterolemic homozygotes with defined receptor defects. J Clin Invest, 1990. 86(4): p. 1306-12.

46. Mamo JC, et al. Accumulation of chylomicron remnants in homozygous subjects with familial hypercholesterolaemia. Eur J Clin Invest, 1998. 28(5): p. 379-84.

47. Cabezas MC, et al. Delayed chylomicron remnant clearance in subjects with heterozygous familial hypercholesterolaemia. J Intern Med, 1998. 244(4): p. 299-307.

48. Kita T, et al. Hepatic uptake of chylomicron remnants in WHHL rabbits: a mechanism genetically distinct from the low density lipoprotein receptor. Proc Natl Acad Sci U S A, 1982. 79(11): p. 3623-7.

49. Watts GF, et al. Chylomicron remnant metabolism in familial hypercholesterolaemia studied with a stable isotope breath test. Atherosclerosis, 2001. 157(2): p. 519-23.

50. Tremblay AJ, et al. Lack of evidence for reduced plasma apo B48 catabolism in patients with heterozygous familial hypercholesterolemia carrying the same null LDL receptor gene mutation. Atherosclerosis, 2004. 172(2): p. 367-73. 
51. Choi SY, et al. Use of an anti-low density lipoprotein receptor antibody to quantify the role of the LDL receptor in the removal of chylomicron remnants in the mouse in vivo. J Clin Invest, 1991. 88(4): p. 1173-81.

52. Stary HC. The sequence of cell and matrix changes in atherosclerotic lesions of coronary arteries in the first forty years of life. Eur Heart J, 1990. 11 Suppl E: p. 3-19.

53. Simons DB, et al. Noninvasive definition of anatomic coronary artery disease by ultrafast computed tomographic scanning: a quantitative pathologic comparison study. J Am Coll Cardiol, 1992. 20(5): p. 1118-26.

54. Rumberger JA, et al. Coronary artery calcium area by electron-beam computed tomography and coronary atherosclerotic plaque area. A histopathologic correlative study. Circulation, 1995. 92(8): p. 2157-62.

55. Ringqvist I, et al. Prognostic value of angiographic indices of coronary artery disease from the Coronary Artery Surgery Study (CASS). J Clin Invest, 1983. 71(6): p. 1854-66.

56. Baumgart $\mathrm{D}$, et al. Comparison of electron beam computed tomography with intracoronary ultrasound and coronary angiography for detection of coronary atherosclerosis. J Am Coll Cardiol, 1997. 30(1): p. 57-64.

57. Detrano R, et al. Coronary calcium as a predictor of coronary events in four racial or ethnic groups. N Engl J Med, 2008. 358(13): p. 1336-45.

58. Erbel R, et al. Coronary risk stratification, discrimination, and reclassification improvement based on quantification of subclinical coronary atherosclerosis: the Heinz Nixdorf Recall study. J Am Coll Cardiol, 2010. 56(17): p. 1397-406. 
59. Schmermund A, et al. Comparison of electron-beam computed tomography and intracoronary ultrasound in detecting calcified and noncalcified plaques in patients with acute coronary syndromes and no or minimal to moderate angiographic coronary artery disease. Am J Cardiol, 1998. 81(2): p. 141-6.

60. Emond $\mathrm{M}$, et al. Long-term survival of medically treated patients in the Coronary Artery Surgery Study (CASS) Registry. Circulation, 1994. 90(6): p. 2645-57.

61. Erbel R, et al. Electron-beam computed tomography for detection of early signs of coronary arteriosclerosis. Eur Heart J, 2000. 21(9): p. $720-32$.

62. Lieber A, Jorgens J. Cinefluorography of coronary artery calcification. Correlation with clinical arteriosclerotic heart disease and autopsy findings. Am J Roentgenol Radium Ther Nucl Med, 1961. 86: p. 1063-72.

63. Raggi P. Coronary calcium on electron beam tomography imaging as a surrogate marker of coronary artery disease. Am J Cardiol, 2001. 87(4A): p. 27A-34A.

64. Arad $\mathrm{Y}$, et al. Prediction of coronary events with electron beam computed tomography. J Am Coll Cardiol, 2000. 36(4): p. 1253-60.

65. Schmidt $\mathrm{HH}$, et al. Relation of cholesterol-year score to severity of calcific atherosclerosis and tissue deposition in homozygous familial hypercholesterolemia. Am J Cardiol, 1996. 77(8): p. 575-80.

66. Schroeder S, et al. Non-invasive characterisation of coronary lesion morphology by multi-slice computed tomography: a promising new technology for risk stratification of patients with coronary artery disease. Heart, 2001. 85(5): p. 576-8. 
67. Klingenbeck-Regn K. et al. Subsecond multi-slice computed tomography: basics and applications. Eur J Radiol, 1999. 31(2): p. 110-24.

68. Dewey $\mathrm{M}$, et al. Noninvasive coronary angiography by 320-row computed tomography with lower radiation exposure and maintained diagnostic accuracy: comparison of results with cardiac catheterization in a head-to-head pilot investigation. Circulation, 2009. 120(10): p. 867-75.

69. Ohnesorge B, et al. Cardiac imaging by means of electrocardiographically gated multisection spiral CT: initial experience. Radiology, 2000. 217(2): p. 564-71.

70. Santos RD, et al. Detection of subclinical atherosclerosis by electron beam tomography in females with heterozygous familial hypercholesterolaemia. Heart, 2004. 90(1): p. 92-4.

71. Miname $\mathrm{MH}$, et al. Evaluation of subclinical atherosclerosis by computed tomography coronary angiography and its association with risk factors in familial hypercholesterolemia. Atherosclerosis, 2010. 213(2): p. 486-91.

72. Martinez LR, et al. No correlation and low agreement of imaging and inflammatory atherosclerosis' markers in familial hypercholesterolemia. Atherosclerosis, 2008. 200(1): p. 83-8.

73. McGowan MP. There is no evidence for an increase in acute coronary syndromes after short-term abrupt discontinuation of statins in stable cardiac patients. Circulation, 2004. 110(16): p. 2333-5.

74. Agatston AS, et al. Quantification of coronary artery calcium using ultrafast computed tomography. J Am Coll Cardiol, 1990. 15(4): p. 827-32.

75. Zlatkis A, Zak B. Study of a new cholesterol reagent. Anal Biochem, 1969. 29(1): p. 143-8. 
76. Mesquita $\mathrm{CH}$. Cinética do quilomícron Marcado com 3H-TG e 14C-CE. Análise compartimental auxiliar. 1994, São Paulo: Instituto de Pesquisas Energéticas e Nucleares-IPEN.

77. Sowby F. Radiation protection. 1984, Oxford.

78. Smith E. Dose estimate tecniques-Nuclear medicine physics, instrumentation and agents. 1977.

79. Miller DN, et al. Evaluation and optimization of DNA extraction and purification procedures for soil and sediment samples. Appl Environ Microbiol, 1999. 65(11): p. 4715-24.

80. Miller DN. Evaluation of gel filtration resins for the removal of PCRinhibitory substances from soils and sediments. J Microbiol Methods, 2001. 44(1): p. 49-58.

81. Kolovou GD, Kostakou PM, Anagnostopoulou KK. Familial hypercholesterolemia and triglyceride metabolism. Int J Cardiol, 2011. 147(3): p. 349-58.

82. Gouni-Berthold I, et al. Effects of ezetimibe and/or simvastatin on LDL receptor protein expression and on LDL receptor and HMG-CoA reductase gene expression: a randomized trial in healthy men. Atherosclerosis, 2008. 198(1): p. 198-207.

83. Bowler A, Redgrave TG, Mamo JC. Chylomicron-remnant clearance in homozygote and heterozygote Watanabe-heritable-hyperlipidaemic rabbits is defective. Lack of evidence for an independent chylomicronremnant receptor. Biochem J, 1991. 276 ( Pt 2): p. 381-6.

84. Hussain MM, et al. Chylomicron metabolism in normal, cholesterol-fed, and Watanabe heritable hyperlipidemic rabbits. Saturation of the sequestration step of the remnant clearance pathway. $\mathrm{J}$ Biol Chem, 1995. 270(15): p. 8578-87. 
85. Herz J, et al. Initial hepatic removal of chylomicron remnants is unaffected but endocytosis is delayed in mice lacking the low density lipoprotein receptor. Proc Natl Acad Sci U S A, 1995. 92(10): p. 4611-5.

86. Eriksson $\mathrm{M}$, et al. Non-steady-state kinetics of low density lipoproteins in man: studies after plasma exchange in healthy subjects and patients with familial hypercholesterolaemia. Eur J Clin Invest, 1993. 23(11): p. 746-52.

87. Twickler TB, et al. High dose of simvastatin normalizes postprandial remnant-like particle response in patients with heterozygous familial hypercholesterolemia. Arterioscler Thromb Vasc Biol, 2000. 20(11): p. 2422-7.

88. Dane-Stewart CA, et al. Elevated apolipoprotein B-48 and remnant-like particle-cholesterol in heterozygous familial hypercholesterolaemia. Eur J Clin Invest, 2001. 31(2): p. 113-7.

89. Moorjani S, et al. Mutations of low-density-lipoprotein-receptor gene, variation in plasma cholesterol, and expression of coronary heart disease in homozygous familial hypercholesterolaemia. Lancet, 1993. 341(8856): p. 1303-6.

90. Gudnason V, Day IN, Humphries SE. Effect on plasma lipid levels of different classes of mutations in the low-density lipoprotein receptor gene in patients with familial hypercholesterolemia. Arterioscler Thromb, 1994. 14(11): p. 1717-22.

91. Gaudet D, et al. Relationships of abdominal obesity and hyperinsulinemia to angiographically assessed coronary artery disease in men with known mutations in the LDL receptor gene. Circulation, 1998. 97(9): p. 871-7. 
92. Cianflone K, Paglialunga S, Roy C. Intestinally derived lipids: metabolic regulation and consequences--an overview. Atheroscler Suppl, 2008. 9(2): p. 63-8.

93. Rivellese $A A$, et al. Effects of monounsaturated vs. saturated fat on postprandial lipemia and adipose tissue lipases in type 2 diabetes. Clin Nutr, 2008. 27(1): p. 133-41.

94. Karpe F, et al. Quantification of postprandial triglyceride-rich lipoproteins in healthy men by retinyl ester labeling and simultaneous measurement of apolipoproteins B-48 and B-100. Arterioscler Thromb Vasc Biol, 1995. 15(2): p. 199-207.

95. Nordestgaard BG, et al. Nonfasting triglycerides and risk of myocardial infarction, ischemic heart disease, and death in men and women. JAMA, 2007. 298(3): p. 299-308.

96. Bansal S, et al. Fasting compared with nonfasting triglycerides and risk of cardiovascular events in women. JAMA, 2007. 298(3): p. 309-16. 